\title{
Phreatic eruption dynamics derived from deposit analysis: a case study from a small, phreatic eruption from Whakāri/White Island, New Zealand
}

\author{
Geoff Kilgour ${ }^{{ }^{*}} \mathbb{D}$, Stephanie Gates ${ }^{2}$, Ben Kennedy ${ }^{2}$, Aaron Farquhar ${ }^{2}$, Ame McSporran $^{2}$ and Cameron Asher ${ }^{1}$
}

\begin{abstract}
On 27 April 2016, White Island erupted in a multi-pulse, phreatic event that lasted for $40 \mathrm{~min}$. Six, variably sized pulses generated three ballistic ejections and at least one pyroclastic surge out of the inner crater and onto the main crater floor. Deposit mapping of the pyroclastic surge and directed ballistic ejecta, combined with numerical modelling, is used to constrain the volume of the ejecta and the energetics of the eruption. Vent locations and directionality of the eruption are constrained by the ballistic modelling, suggesting that the vent/s were angled towards the east. Using these data, a model is developed that comports with the field and geophysical data. One of the main factors modifying the dispersal of the eruption deposits is the inner crater wall, which is $\sim 20 \mathrm{~m}$ high. This wall prevents some of the pyroclastic surge and ballistic ejecta from being deposited onto the main crater floor but also promotes significant inflation of the surge, generating a semi-buoyant plume that deposits ash high on the crater walls. While the eruption is small volume, the complexity determined from the deposits provides a case study with which to assess the relatively frequent hazards posed by active volcanoes that host hydrothermal systems. The deposits of this and similar eruptions are readily eroded, and for complete understanding of volcanic hazards, it is necessary to make observations and collect samples soon after these events.
\end{abstract}

\section{Introduction}

Phreatic eruptions are generated by either ascending fluids heated by magma (Browne and Lawless 2001), generally in a volcano hydrothermal system, or by the release and ascent of magmatic gas into a sealed or partially sealed hydrothermal system (e.g. Jolly et al. 2010). This style of eruption is difficult to forecast (despite recent attempts, e.g. Chardot et al. (2015); de Moor et al. (2016); Girona et al. (2018)), partly because the driving mechanisms can be complicated and involve potentially rapid onsets. To compound poor forecasting, these areas are frequently popular with tourists (Fitzgerald et al. 2017) and eruption hazard footprints may be poorly

\footnotetext{
*Correspondence: g.kilgour@gns.cri.nz

${ }^{1}$ GNS Science, Wairakei Research Centre, 114 Karetoto Rd, Taupo, New Zealand

Full list of author information is available at the end of the article
}

constrained creating an elevated risk to life and safety. Forecasting is difficult because (1) overpressures develop over localised areas (i.e. 10's of $\mathrm{m}^{2}$ ), making them very difficult to monitor adequately, especially in crater lakes or within active hydrothermal systems (Edwards et al. 2017), and (2) the timescales of overpressure seem to vary from near instantaneous to many weeks or months (e.g. Barberi et al. 1992 and references therein; Jolly et al. 2010; Kato et al. 2015).

Coupled with the explosive nature of this style of eruption, albeit with a relatively small volume of ejecta, phreatic eruptions pose a significant threat to people and infrastructure near the vent area (e.g. Kilgour et al. 2010; Fitzgerald et al. 2014; Kaneko et al. 2016; Williams et al. 2017). Due to recent fatalities (e.g. Kaneko et al. 2016), there is a renewed research focusing on phreatic eruptions and a growing body of work that can be used to investigate the array of mechanisms that generate these 
events (e.g. Mayer et al. 2015; Montanaro et al. 2016a, b). Indeed, with careful fieldwork, modelling and experimental work, the range of processes involved in phreatic eruptions can be better understood and the potential to forecast with adequate warning will improve.

In water-bearing hydrothermal environments, the hazard footprint of a phreatic eruption is dominated by ballistic ejecta, pyroclastic surges and fallout of ash from steam plumes. Most damage is inflicted from the ballistic and surge components and with careful sample description and collection, it is possible to take the deposit data and recreate the emplacement dynamics of the eruption through time (e.g. Maeno et al. 2016) to create a timevariable hazard footprint. To maximise the accuracy of the event reconstructions, it is important to integrate the deposit data with acoustic, seismic, meteorological and deformation data. Cases of phreatic eruptions where many volcanological disciplines have come together are rare and include the 2007 eruption of Ruapehu (Christenson et al. 2010; Jolly et al. 2010; Kilgour et al. 2010), 2012 eruption of Te Maari, Tongariro (e.g. Crouch et al. 2015; Jolly et al. 2014) and 2014 eruption at Ontake, Japan (e.g. Kaneko et al. 2016; Tsunematsu et al. 2016).

Faithful records of phreatic eruptions are sparse because these events are impulsive, short-lived, and are therefore not always witnessed or recorded, and the near complete lack of preservation potential in the geological record preclude a true inventory of these events. In rare cases, such as that compiled for Ruapehu, New Zealand (Scott 2013), a detailed account of phreatic versus magmatic eruptions over the last $>150$ years can be developed, providing the basis for quantifying volcanic risk (Strehlow et al. 2017).

In New Zealand, there have been six phreatic eruptions that ejected material beyond the immediate crater area over the past 15 years (Ruapehu 2007; White Island in 2012, 2013 and 2016; Tongariro-August and November 2012) that have ejected material beyond the immediate crater area. The Ruapehu (Kilgour et al. 2010) and Te Maari (Lube et al. 2014) eruptions were directly witnessed, while for the 2012 and 2013 eruptions at White Island, webcam footage was used to elucidate eruption processes (Kilgour and Bowyer 2015) providing useful comparisons with the geological data. The most recent White Island eruption occurred on 27 April 2016, at $10 \mathrm{pm}$ (local time) and because of the timing the eruption was not witnessed by visitors to the island or on the webcams because of low light conditions at the time. It was, however, recorded by a network of portable seismometers, and acoustic sensors that recorded six distinct explosions or pulses of varying energy release (Walsh et al. 2019). In the aftermath of this event, we made observational flights within $24 \mathrm{~h}$ and ground-based assessments in the subsequent weeks and months and a drone-based Structure-From-Motion (SFM) survey of the crater floor $\sim 8$ months after the event when the lake had evaporated/drained. Here, we use this eruption and the detailed analysis of the resulting deposits to examine the energetics, volume, and emplacement dynamics of the eruption sequence and tie this to the geophysical (Walsh et al. 2019) record. In this way, our companion papers highlight strategies for unravelling the complexity of a multi-phase eruption sequence using disparate analysis tools.

\section{White Island}

Whakāri/White Island (here referred to as White Island) is New Zealand's most active volcano and has been in a near constant state of unrest or eruption in recent history. Located $\sim 50 \mathrm{~km}$ off the east coast of the North Island, the island sits at the northerly end of the Taupo Volcanic Zone, a rifted volcanic arc caused by the oblique, westward subduction (Fig. 1). Only a small portion of the volcano edifice is subaerial, while the bulk of the $(16 \mathrm{~km} \times 18 \mathrm{~km})$ edifice is submarine (Duncan 1970). The subaerial portion of the volcano consists of two, overlapping cones that reach $\sim 300 \mathrm{~m}$ asl. In the main crater floor, there are three identified subcraters, of which all the historical activities have been focussed in the western subcrater, a depression $\sim 20-25 \mathrm{~m}$ lower than the main crater floor. This western subcrater is periodically infilled by a hot $\left(30-50{ }^{\circ} \mathrm{C}\right)$, acidic $(-1$ to $0 \mathrm{pH})$ crater lake (Houghton and Nairn 1991; Werner et al. 2008; Edwards et al. 2017).

The composition of exposed deposits and historical White Island eruptions is dominantly andesite-dacite with rare high-Mg andesite (Cole et al. 2000). The most recently analysed magmatic eruptions at White Island occurred during the long-lived eruption episode between 1976 and 2000. During that episode, Strombolian and phreatomagmatic eruptions occurred regularly (Houghton et al. 1983; Houghton and Nairn 1991), fuelled by repeated mafic injections (Kilgour et al. 2016). More broadly and when compared to global arc andesites (Wallace 2005; Plank et al. 2013), White Island magmas are unusually hot and dry allowing for magmas to reside at very shallow depths for long periods (Esposito et al. 2014; Kilgour et al. 2016).

More recently, a period of heightened unrest and periodic explosive eruptions occurred between 2012 and 2013, along with the effusive growth of a small lava dome in late 2012. The largest eruptions during this period were recorded on 5 August 2012, and 11 and 20 October 2013 (Chardot et al. 2015). During these events, steam and ash plumes were generated as well as ballistic ejecta and pyroclastic surges. While ballistics of rock and 


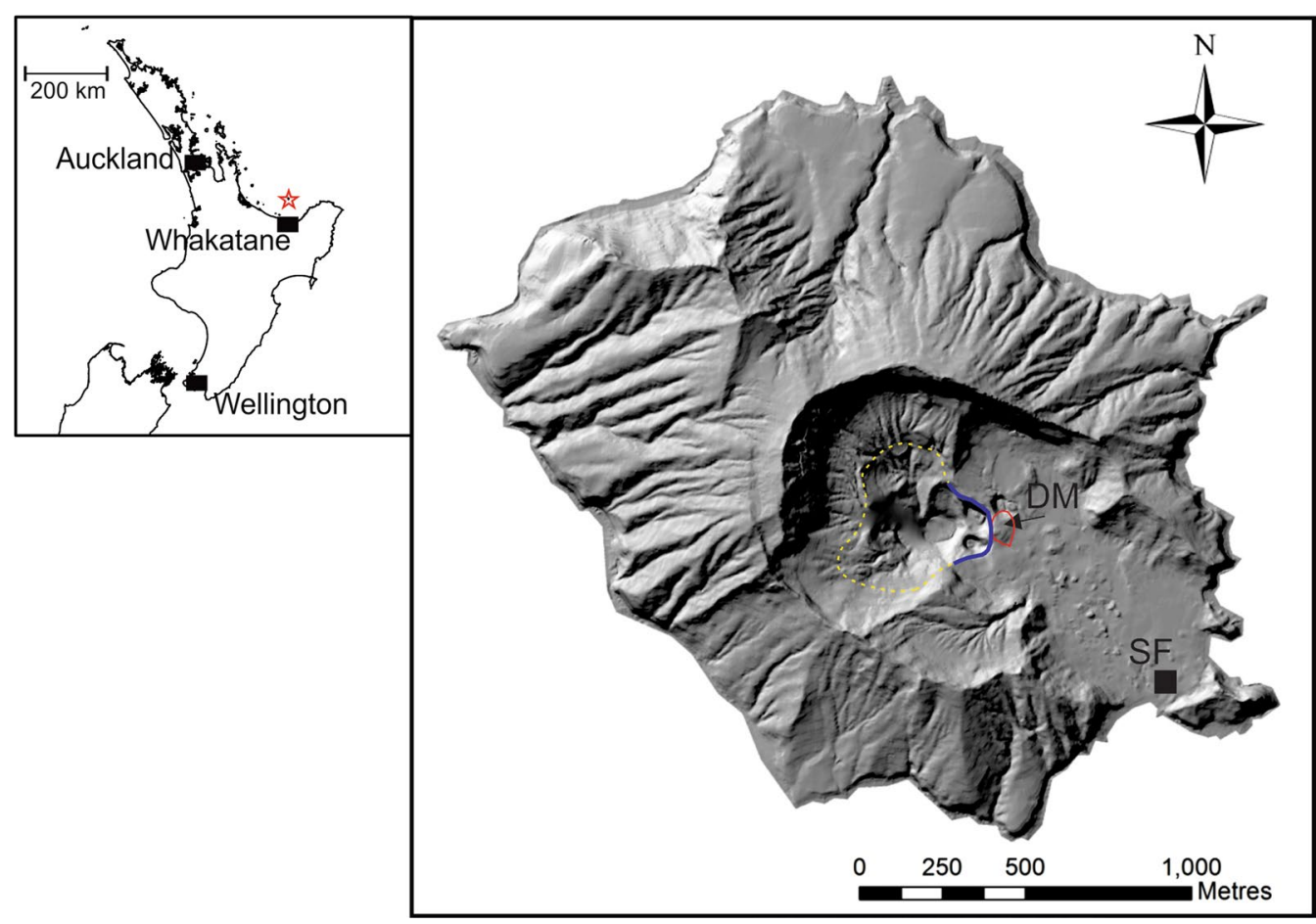

Fig. 1 (Inset) Located near Whakatane $50 \mathrm{~km}$ offshore of the North Island of New Zealand, White Island (red star) is a small subaerial portion of a much larger andesite-dacite edifice. Hillshade model of White Island shows the main topographic features, including the inner crater to the west (yellow dashed region), the crater rim (purple line) and key features of Donald Mound (DM) and the Sulphur Factory (SF)

mud (Edwards et al. 2017) are readily able to fly beyond the inner crater, dilute pyroclastic density currents are inhibited by the $\sim 20$-m-high crater wall. This confinement of surges to the inner crater is noted throughout some of the 2012-2013 activity except for the 11 October 2013 eruption. During that event, a surge was able to surmount the inner crater wall and flow towards the east reaching a distance of $\sim 500 \mathrm{~m}$ from the vent (Kilgour and Bowyer 2015). These eruptions clearly pose a significant hazard to the tourists that visit the island.

We focus on the 27 April 2016 event to unpick the eruption dynamics so that we have a better understanding of these types of phenomena at White Island, and also as an analogue phreatic eruption that was well monitored and where field visits were made soon after to collect potentially perishable sample data. To unravel this event, we describe the eruption deposits and the relative timing between the ballistic pulses (derived from the seismoacoustic data) and surge generation. We refine our timeline and impacts with the geophysical monitoring data (Walsh et al. 2019) to determine the number of pulses that ejected material beyond the crater area. Finally, we illustrate the emplacement dynamics and implied hazard of phreatic eruptions in the area proximal to the crater lake.

\section{Methods}

\section{Field methods}

The day after the eruption (28 April 2016), aerial observations were made (Fig. 2), but due to the potentially elevated risk of future activity (Deligne et al. 2018), staff time was limited on the island. Because of this time restriction, we made a short visit (19 May 2016 for $\sim 2 \mathrm{~h}$ ) to collect samples and photographs of the ash deposit and near-surface blocks that were variably buried by ash, for later analyses (Fig. 3). The deposits from the eruption consisted of both a fine to coarse ash deposit (Fig. 3) across most of the crater floor-we will describe this deposit and its mode of emplacement below-and a more restricted distribution of large blocks with uncommon impact craters-which we interpret to being emplaced ballistically. Where possible, we collected thickness measurements of the ash deposit and made notes of the distribution of ballistic blocks along our traverse to the vent area and on the way back to the helicopter. This meant that the full crater floor was not sampled nor were deposit measurements made to obtain an ideal thickness map. Nevertheless, we collected 10 samples for grain size analysis and made 32 thickness measurements of the ash deposit. We also collected 12 ballistic, blocksized (10-40 cm across) samples from 3 localities (Fig. 3). 

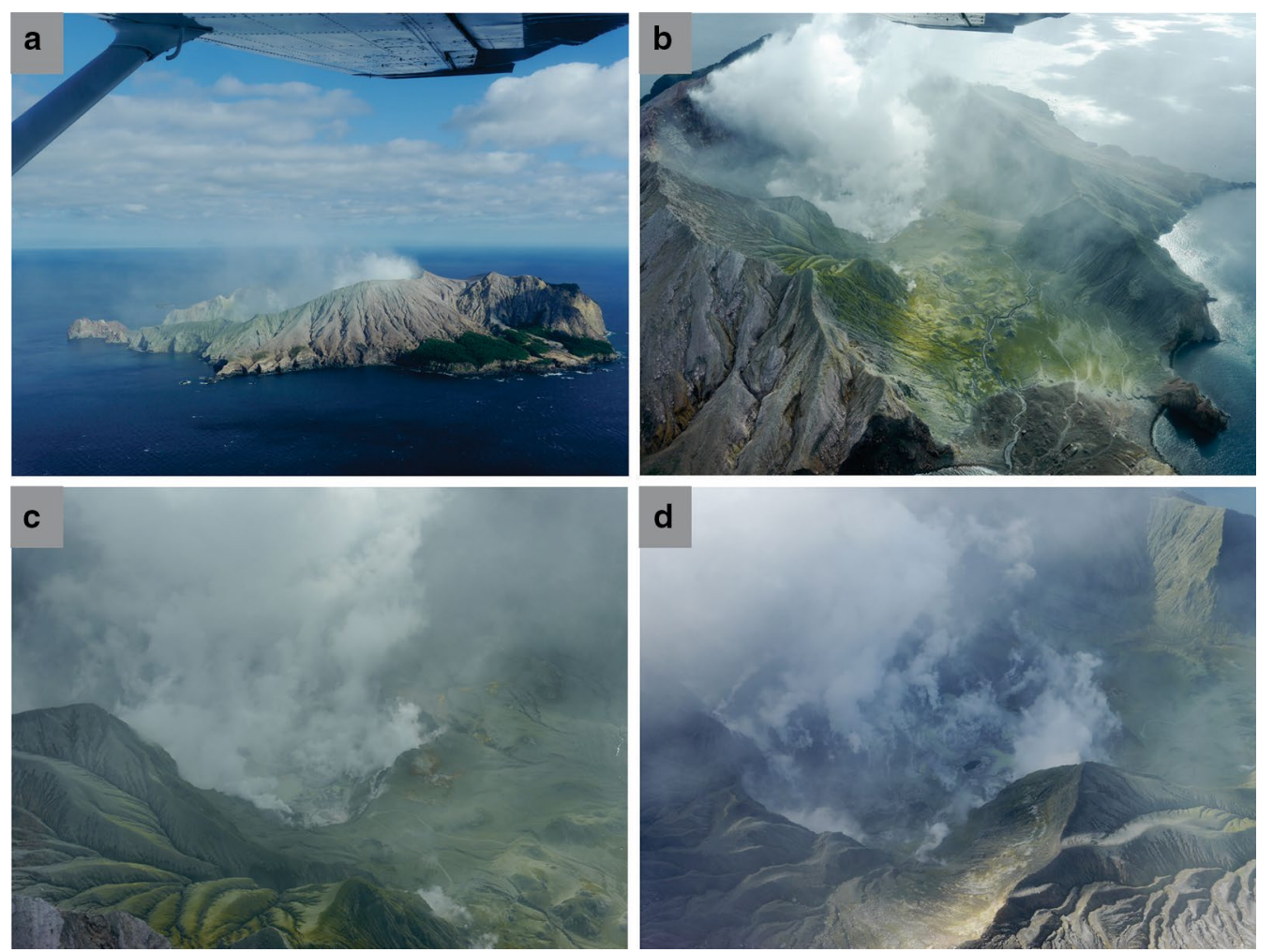

Fig. 2 Aerial photographs taken of the island on the 29 April 2016. a View to the south showing ash distribution on the northern crater wall. $\mathbf{b}$ View of the main crater floor showing the distribution extent of the pyroclastic surge (yellow-green coloured) to the bottom right of the image. $\mathbf{c}$ Image of the eastern edge of the vent area and with high altitude ash deposition in the immediate foreground. $\mathbf{d}$ Inner crater image showing the extensive steaming ground and the diffuse emission sources. This inner crater area is usually submerged beneath a hot, acidic crater lake

Later, on 2 June 2016, we again visited the island to more specifically sample ballistic ejecta for later density measurements, along with mineralogy and lithology descriptions. During this visit, we used a $1 \mathrm{~m}^{2}$ aluminium frame and collected 28 images of the ejecta in a grid within the ballistic apron, which were later used for image analysis. This frame enabled scaled images to be obtained rapidly, reducing our time within the crater. Images obtained in this way were mostly used to distinguish the relative proportions of the ballistic ejecta and their spatial relationship to the ash deposit.

\section{Laboratory methods}

Samples of the ash deposit were oven-dried and then dry-sieved. The pan fraction was then analysed using a Beckman Coulter LS 13320 SW laser particle size analyser with an aqueous liquid module. We then merged the sieved and lasered data together despite the known issues converting mass and volume between the two techniques to generate the grain size distribution at each sample location. We made epoxy mounted grain mounts of the bulk ash sample for low vacuum, component analysis on a JEOL NEOSCOPE 6000plus Desktop SEM at GNS
Science, Wairakei. The ballistic samples were oven-dried for $48 \mathrm{~h}$ at $60{ }^{\circ} \mathrm{C}$, weighed and then used a water-filled vacuum chamber to calculate the wet and dry bulk density of the samples. These measurements were complimented by 94 drilled cores of known volume cut from 24 samples measured using a Micrometrics Accupyc 1340 helium pycnometer at University of Canterbury (Farquhar 2018).

\section{Image analysis for block components}

Ballistic ejecta were categorised into two lithological endmembers (yellow/white and grey) for bimodal image processing. These two ballistic types are physically, chemically and visually distinct. This visual difference, with approximately half of the ballistic blocks dominantly yellow and white, is a discoloration which is attributed to hydrothermal alteration to a sulphate-dominated assemblage of gypsum, alunite and other hydrothermal minerals (Farquhar 2018). Hydrothermally altered blocks are measured to be lower density and higher porosity than less altered blocks. Less altered blocks are mostly grey and black, hosting primary volcanic textures and reflecting their origin as andesitic lava blocks. 


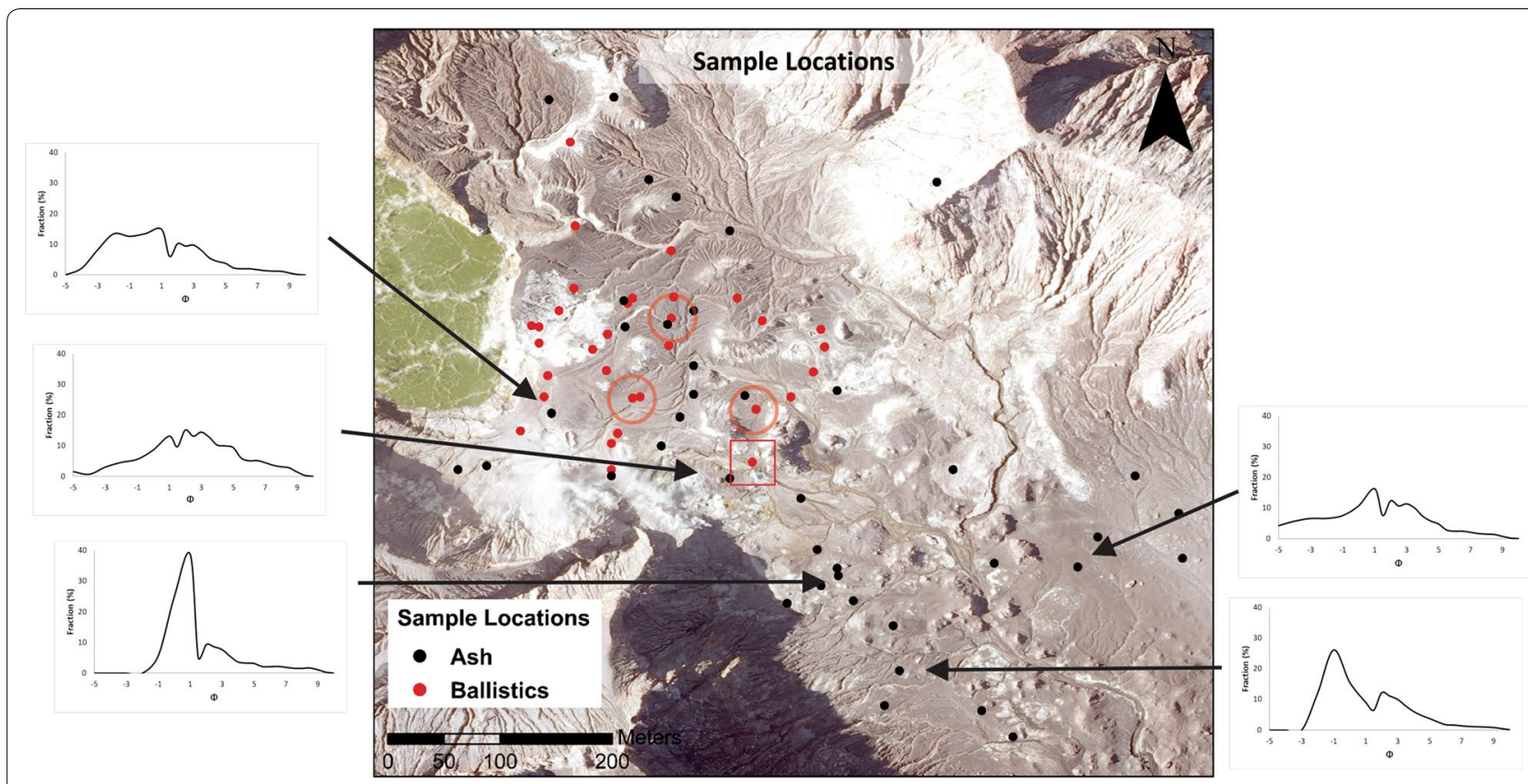

Fig. 3 Locations of deposit sampling are shown for both the ash-rich (black dots) and ballistic (red dots) ejecta. The vent of the eruption sequence is located to the top left of the image - this image was taken when a crater lake (green water body) had infilled the western subcrater. Note that site 35 (red square) was excluded from the modelling analysis due to its close proximity to the southern crater wall. Ballistic samples were collected from sites denoted by a red circle. Grain size distributions of selected ash-rich deposit locations are also shown

The distribution of ballistics was mapped based on photographs within CorelDRAW using the free hand drawing tool to outline the blocks. Once all blocks in the image were traced, the file was exported into ImageJ where the one-square-metre frame (Fig. 4) was used to set a scale and the option "Particle Analysis" was used to determine the area of each clast. Clasts that were outlined in ImageJ were translated into an equivalent diameter assuming a circular area. It is worth emphasising one caveat of the ballistic point data, since some clasts were partially or completely buried by ash, this made the ballistic volume estimation a minimum. Additionally, White Island's crater lake likely conceals much of the ejecta that was unable to surmount the crater rim. Therefore, an attempt at quantifying the number lost from mapping is determined in the modelling results explained below.

As a first-order approximation, the total volume of ballistics within each square-metre-field photograph was estimated by approximating each clast as a sphere. The individually calculated ballistic volumes were summed to

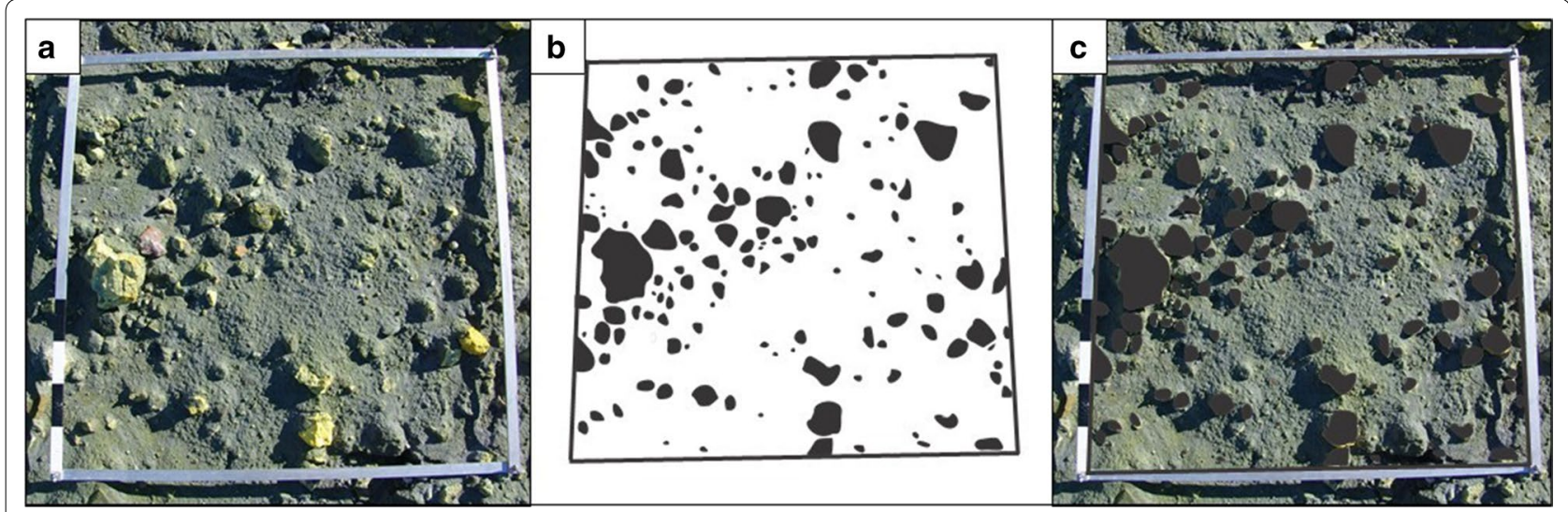

Fig. 4 An example of image analysis from framed images in the field (a), processed to binary (b) and with the overlay (c) 
calculate a total volume of ballistic ejecta. Many ballistics were covered by the ash deposit and so the proportion of ballistics with $>1 \mathrm{~cm}$ of ash coating was also analysed. Based on the images taken, the volumes of covered ballistics were estimated to be distributed evenly among lowand high-density ballistics, based on the respective ratio between the two within each square metre.

The ratio of volumes between low- and high-density ballistics was then mapped in ArcMap. The volume isopleths of low density, high density, and all ballistics was interpolated using the SPLINE tool. Field observations (noted above) of the ballistic apron extent were used to constrain the perimeter of the resulting isopleth map.

\section{Drone-based digital surface/elevation model (DS/EM)}

The White Island crater DEM is derived using Structure-from-Motion (SFM) photogrammetry in Agisoft Photoscan 1.3.0. Photographs were obtained using a DJI Phantom 4 UAV with a stock $1 / 2.3$ " sensor, 94-degree FOV camera on 20 December 2016, flown both manually and with Pix4D double grid missions at a height of $\sim 50 \mathrm{~m}$ agl (Fig. 5). A total of 1199 images were captured, with 1193 being successfully aligned by Photoscan. Photograph alignment quality was increased after initial sparse cloud creation using Photoscan's Gradual Selection tool to remove images with high reprojection error, high reconstruction uncertainty and low projection accuracy. A dense point cloud was created using "High" settings, generating a total of 228 million points. The survey used 17 ground control points (GCPs), 14 of which were used to re-project the survey in geospace and three as check points. The final DEM output had a spatial resolution of $0.059 \mathrm{~m}$ and $X / Y / Z$ errors of $0.115,0.177$, and $0.121 \mathrm{~m}$, respectively. As this high-spatial resolution UAV surface model only incorporated the inner crater, it was combined with a $1 \mathrm{~m}$ resolution DEM from 2011 covering the remainder of White Island and in the process was resampled to 1 and $5 \mathrm{~m}$ resolutions to also reduce processing times during ballistic modelling.

\section{D volcanic ballistic trajectory modelling}

As the eruption was unwitnessed, the number of eruptive pulses that contributed to the ballistic field could only be determined based on seismic and acoustic signals. White Island hosts two permanent Geonet seismometers with acoustic sensors (Walsh et al. 2019) and due to the ongoing higher activity level since 2000, three additional temporary seismometers were on the island at the time of

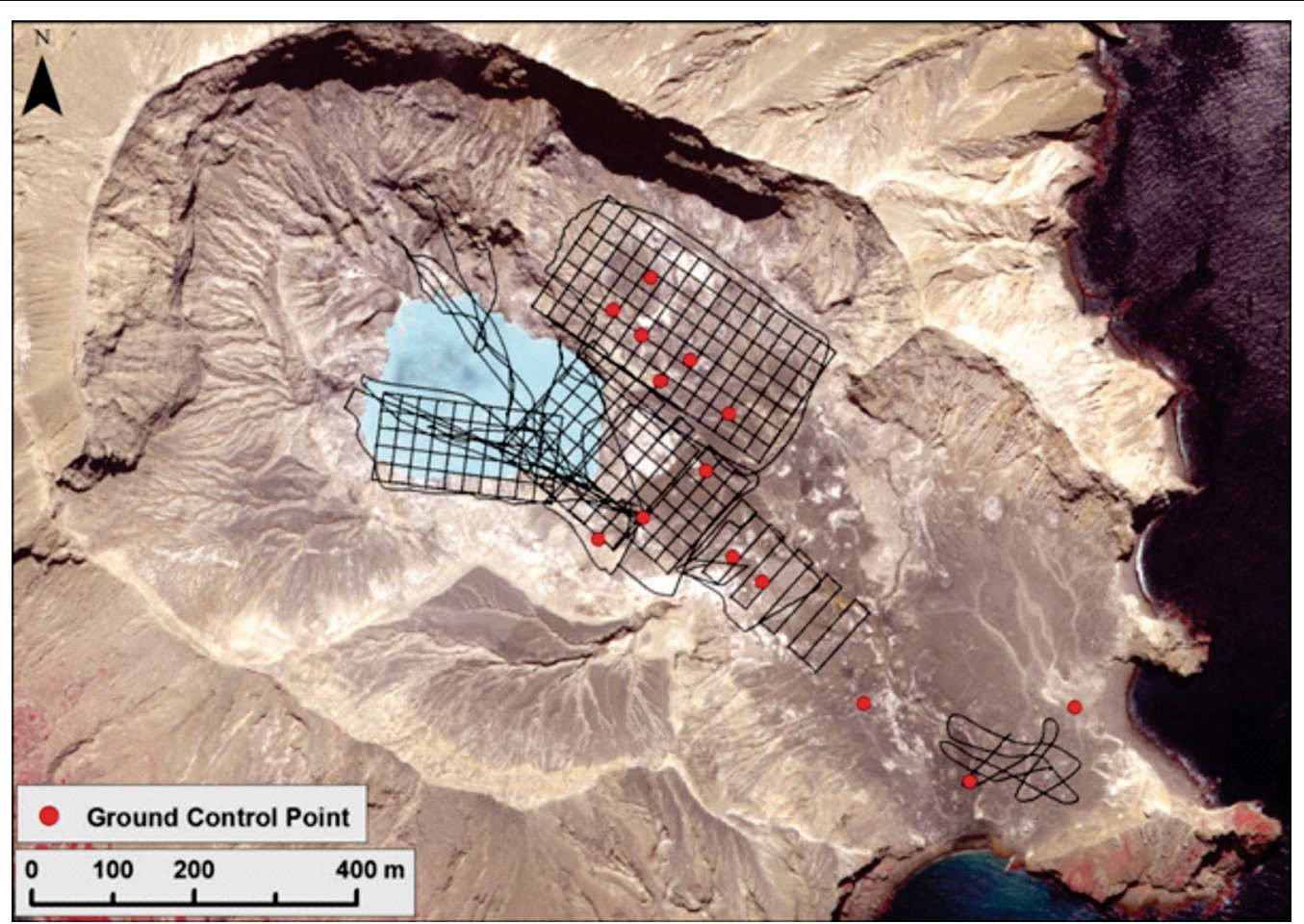

Fig. 5 Survey path of the drone-based digital elevation model of White Island from December 2016. We focussed most of the photogrammetry survey towards the western subcrater, which is periodically infilled by a warm, acidic lake. At the time, there was no lake present and this survey attempted to quantify the topography of the inner crater basin $~ 8$ months after the eruption described here. We used 16 ground control points that were co-located with survey pegs-labelled in red) 
eruption. The acoustic sensors on White Island recorded at least six separate pressure pulses (Walsh et al. 2019) which here we presume to indicate onset of an eruptive pulse (Table 1).

Following methods of Fitzgerald et al. (2014) and Tsunematsu et al. (2016) model parameters were constrained by eruption data and progressively and systematically refined to improve best fit with the ballistic deposits. As mentioned above, the April eruption produced six energetic pulses (Walsh et al. 2019), with variable energies. This added complexity of a multi-pulse event required us to assess a range of plausible scenarios to match the observed ballistic distribution to the eventual model runs in a series of forward models. For the purposes of this paper, we modelled both a single large pulse and three smaller pulses to explore two end member scenarios.

It was not possible to measure the total number of ballistics in the field including the blocks that landed within the crater. The total number of blocks ejected was estimated based on fitting the number of blocks within each metre square with the modelled output within that area.

Comparison of modelled and mapped data was undertaken by matching the ballistic field shape and comparing the modelled ballistics per $\mathrm{m}^{2}$ with the field data. The mapped ballistics density was matched to the modelled density within the adjacent $25 \mathrm{~m}^{2}$ area due to the high local variability in modelled spatial density and the small area sampled in the field. Thirty-one of the 33 sites photographed were used to assess the spatial distribution of blocks ejected during the April White Island eruption. Site 35 was excluded from analysis due to (1) a proximity the crater wall rock fall sites, (2) an unusual size distribution and (3) a distinct orange weathered lithological character similar to the overlying cliff. This evidence pointed to a significant portion of these clasts having originated through rock fall.

The size distribution and density of particles ejected from a volcanic vent are important factors in the transport and spatial distribution of ejected blocks. Taking the results of the image analysis, a total of 4773 clasts were identified through photographs and traced. Block diameters were then calculated leading to a total size distribution of particles from $1.07 \mathrm{~cm}$ to $42.3 \mathrm{~cm}$ with an average calculated clast diameter of $2.14 \mathrm{~cm}$. The mean particle diameter used in the model was $7.91 \mathrm{~cm} \pm 4.2 \mathrm{~cm}$, with a maximum diameter of $42 \mathrm{~cm}$ and a minimum diameter of $5 \mathrm{~cm}$, as ballistic trajectories of particles below $5 \mathrm{~cm}$ cannot be accurately modelled using Ballista. We used an average bulk density of $1691 \mathrm{~kg} \mathrm{~m}^{-3}$, with a standard deviation of $311 \mathrm{~kg} \mathrm{~m}^{-3}$ from measurements of 94 cores.

Ejection angle and direction are constrained by a mean ejection from the horizontal spread (inclination angle) around that angle and a bearing (direction). A vertical, axis-symmetric eruption generally creates circular ballistic field distributions (de Michiele Vitturi et al. 2010; Taddeucci et al. 2017). At White Island, the furthest distance that blocks reached-towards the ESE-and the field shape is elongated towards the easterly direction. Fieldwork confirmed the edge of the ballistic field was accessible in most of the crater while restricted access to the south and lack of access to the northwest of the crater lake lead to some uncertainty. However, ESE directionality is also supported by the same apparent directionality of ash deposit thickness and the strength of seismic and acoustic signals reaching station WIZ to the east (Walsh et al. 2019). Hence, the ESE direction formed the basis of ballistic modelling directionality. The modelled bearing of each eruption pulse was chosen through best fitting the modelled distribution to the spatial variation change. The choice of ejection angle for the eruption pulses modelled was best fitted following initial iterations with ejection angles of $45^{\circ}$ and then progressively lower angles to improve the model fit. The spread around the ejection angle (inclination angle, Tsunematsu et al. 2014) was determined iteratively to improve the best fit paying attention to the outer limit of the ballistic field.

Table 1 Seismo-acoustic characterisation of the eruption sequence

\begin{tabular}{|c|c|c|c|c|c|c|c|}
\hline Pulse no. & Start & End & Vent location & $\begin{array}{l}\text { Average acoustic } \\
\text { energy }(\mathrm{J})\end{array}$ & Rank & $\begin{array}{l}\text { Average seismic } \\
\text { energy }(J)\end{array}$ & Rank \\
\hline P1 & $09: 35.3$ & $09: 37.3$ & Eastern & $3.99 \times 10^{6}$ & 5 & $6.91 \times 10^{7}$ & 5 \\
\hline P2 & $09: 40.5$ & $09: 42.4$ & Northern & $3.05 \times 10^{6}$ & 6 & $4.08 \times 10^{7}$ & 6 \\
\hline P3 & $09: 48.3$ & $09: 49.4$ & Centre & $8.48 \times 10^{6}$ & 4 & $2.96 \times 10^{8}$ & 2 \\
\hline P4 & 09:54.1 & 09:56.0 & Eastern & $2.15 \times 10^{7}$ & 3 & $2.67 \times 10^{8}$ & 3 \\
\hline P5 & 10:03.4 & 10:04.3 & Eastern & $6.76 \times 10^{7}$ & 2 & $1.88 \times 10^{9}$ & 1 \\
\hline P6 & $10: 11.3$ & $10: 13.1$ & Northern & $1.84 \times 10^{8}$ & 1 & $1.33 \times 10^{8}$ & 4 \\
\hline
\end{tabular}

Acoustic average from stations WIZ and WSRZ. Seismic energy average from permanent and temporary seismic stations WIZ, WSRZ, WI01, WI02, WI04, WI13 (Walsh et al. 2019) 
The speed at which the clasts were ejected was also based on best fit, starting with ejection speeds lower than $100 \mathrm{~m} \mathrm{~s}^{-1}$, due to the significantly smaller distances reached by clasts at White Island as compared to other phreatic eruptions modelled in the literature, such as Mt. Ontake 2014, 111-185 $\mathrm{m} \mathrm{s}^{-1}$ (Oikawa et al. 2016; Tsunematsu et al. 2016) and Te Māri 2012, 165-200 $\mathrm{m} \mathrm{s}^{-1}$ (Fitzgerald et al. 2014; Breard et al. 2014). A best fit was found with ejection speeds of $50 \mathrm{~m} \mathrm{~s}^{-1}$ for Pulse 4, $58 \mathrm{~m} \mathrm{~s}^{-1}$ for Pulse 5 and $65 \mathrm{~m} \mathrm{~s}^{-1}$ for Pulse 6.

Particles ejected during volcanic eruptions are initially influenced by the eruption column gas phase which imparts a reduced drag on particles, until they decouple from the gas phase and travel on essentially ballistic trajectories (Lorenz 1970; Mastin 2001; Fitzgerald et al. 2014). It is assumed in this model iteration that at ejection point the speed of the particles and the gas phase is equal, and hence, the particles are completely coupled with the gas phase. Soon after, the gas velocity decreases while ballistics continue to travel faster than the expanding gas due to inertial effects on the blocks, thereby increasing the relative drag force on the particles over time. At some distance from the vent, the blocks then decouple from the eruption jet completely and travel on essentially parabolic paths. Gas flow velocities modelled range from 50 to $65 \mathrm{~m} \mathrm{~s}^{-1}$ assuming coupling of blocks and gas flow and best fit initial velocity modelling.

The rarity of studies pertaining to gas flow regions in phreatic eruptions means a combination of previous modelling publications and best fit has been used to derive a value for this scenario. Tsunematsu et al. (2016) derived ejection speeds of $145-185 \mathrm{~m} \mathrm{~s}^{-1}$ and a gas flow region of $100 \mathrm{~m}$ when modelling the $2014 \mathrm{Mt}$ Ontake eruption. The eruption at White Island was smaller, with lower ejection speeds; hence, smaller gas flow regions were used and varied with eruption burst size, i.e. smaller bursts have smaller gas flow regions.

The drag coefficient $\mathrm{Cd}$ is a dimensionless number which quantifies the amount of drag force exerted on a particle travelling through air. Alatorre-Ibergüengoitia and Delgado-Granados (2006) found that Cd values depend mainly on shape and texture of the ballistic clast. The closest description of sample types tested by the authors was "Angular shape" and "Smooth surface" texture-this is the best match to the samples observed at White Island hence we used a $\mathrm{Cd}$ value of 0.7 for all clasts.

We modelled the three largest acoustic pulses (Pulses 4, 5 and 6) because the other three were of significantly lower energy and therefore unlikely to produce extracrater ballistics that would contribute to the mapped field. The acoustic energy signature was used over the seismic energy because it is more likely related to the surface expression of ballistic episodes (Jolly et al. 2016). When the average acoustic energy is normalised to the largest burst, the smallest three bursts make up less than $9 \%$ of the acoustic energy combined. While these smaller pulses may have ejected blocks, they are unlikely to exit the $\sim 20$-m-high inner crater wall and travel the $100 \mathrm{~m}$ horizontal distance to the mappable ballistic field.

The general position of each eruptive burst was initially located through seismo-acoustic interpolation by Walsh et al. (2019). This information was paired with additional explosion craters visible in the DEM collected following the eruption (Fig. 5). The complexity of the vent locations fits with the number of bursts interpolated from each, i.e. the "Central" vent location where one burst is attributed to is proximal to a single depression, whereas the "Eastern" location with three bursts is close to a complex area with multiple depressions. The acoustic energy of each pulse determined the relative number of particles in each eruptive pulse in this model (Table 2). The relative acoustic energy of each pulse is assumed to be proportional to the kinetic energy release of each eruption. Kinetic energy $\left(E_{\mathrm{k}}\right)$ of each burst is calculated based on the mass of particles ejection and the velocity at which they are ejected.

$$
E_{\mathrm{k}}=\frac{1}{2} m v^{2}
$$

The width of the vent affects the dynamics of the particles being ejected. Ballista models this effect in terms of the average displacement of particles from the vent centre, the standard deviation of particles from

Table 2 Relative kinetic energy of eruption bursts and consequent number of blocks modelled

\begin{tabular}{|c|c|c|c|c|c|c|c|}
\hline & $\begin{array}{l}\text { Average acoustic } \\
\text { energy }(\mathrm{J})\end{array}$ & $\begin{array}{l}\text { Normalised } \\
\text { to largest (\%) }\end{array}$ & No. particles & $\begin{array}{l}\text { Average } \\
\text { velocity }(\mathrm{m} / \mathrm{s})\end{array}$ & $\begin{array}{l}\text { Ave. block } \\
\text { mass (kg) }\end{array}$ & Kenergy $(\mathrm{J})$ & Normalised (\%) \\
\hline P6 & $1.84 \times 10^{8}$ & 100 & 270,000 & 65 & 0.026 & $154,041,966.54$ & 100 \\
\hline P5 & $6.76 \times 10^{7}$ & 36.74 & 124,500 & 58 & 0.026 & $5,522,547.75$ & 36.71 \\
\hline \multirow[t]{2}{*}{ P4 } & $2.15 \times 10^{7}$ & 11.68 & 53,300 & 50 & 0.026 & $1,757038.83$ & 11.68 \\
\hline & & & & & Total & $22,321,553.11$ & \\
\hline
\end{tabular}


the centre and the maximum displacement, in metres (Tsunematsu et al. 2014). The width of the morphological depressions chosen as vent locations was measured, with the radius representing the maximum displacement from the vent centre and average displacement taken as half way between the centre of the vent and the edge.

For computational efficiency, the merged DEM resolution was reduced to $5 \mathrm{~m}$. As a result, the landing locations of the blocks have a 5-m grid-like artefact, which contributed to the variable spatial density.

\section{Results}

\section{Field observations}

Observations from the first field visits show the vent area to be vigorously steaming, with more than one location showing signs of activity. The inner crater wall near Donald Mound partially collapsed and the lake floor dropped significantly (Fig. 1b-collapse not shown). An explosion had clearly generated a weak plume which deposited ash over the northern outer crater wall, and an ash deposit had been emplaced across most of the crater floor (Figs. 2 and 6). Indeed, the extent of the dominantly ash deposits is readily identified for its distinctive yellow-brown alteration caused by the oxidation of sulphur-rich fluid within the deposits. Based on the extent of the discoloured surface, indicating crater lake and ash deposition, the deposit extends to $\sim 700 \mathrm{~m}$ from the inner crater edge (Fig. 2). Sections dug into the deposit show no signs of bedding (Fig. 7), the grain size distribution is poorly to very poorly sorted, but with the inclusion of distinctly oversized blocks within the deposit, especially within $300-400 \mathrm{~m}$ of the inner crater rim. Blocks are more abundant near the edge of the inner crater wall where the deposit is thickest.

The emplacement mechanism for this dominantly ashrich deposit is not straightforward. Based on the lithofacies, including the grain size distribution, the deposit is either of proximal fall or surge origin, but clues to the mechanism are noted. Firstly, there is clear evidence that both plastic and wooden pegs were sheared off at the base of this deposit (Fig. 7). These locations form part of a semi-permanent site network for repeat theodolite levelling (wooden stakes) and $\mathrm{CO}_{2}$ flux measurements
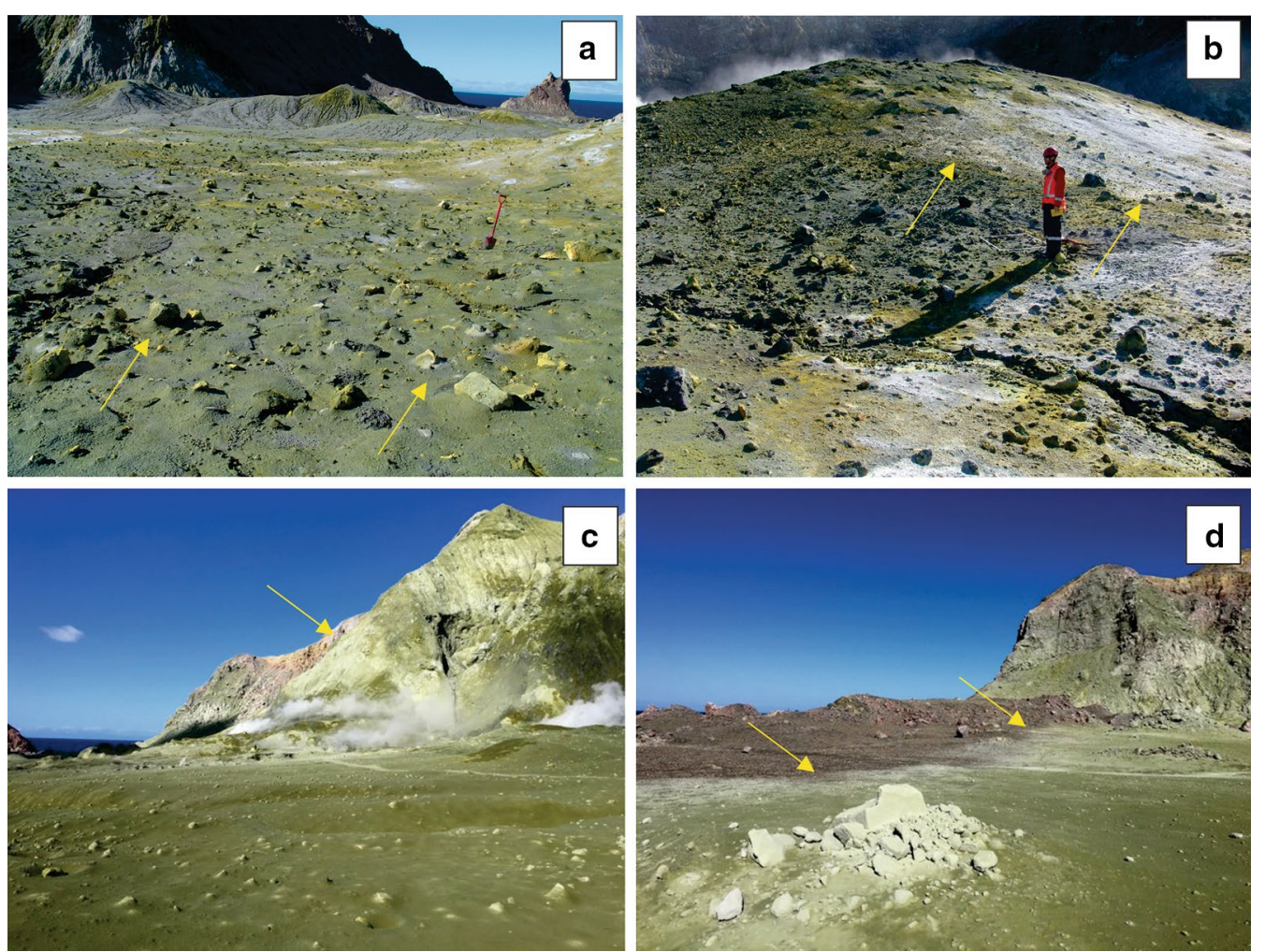

Fig. 6 a Image taken from near the inner crater wall looking to the east. Arrows indicate the preferential burying angle caused by the later parts of the pyroclastic surge partially covering previously ejecta ballistic blocks. $\mathbf{b}$ From the same location as in (a), looking to the north towards Donald Mound (Fig. 1), a positive topographic feature. Note the sharp ballistic margin (arrow). c Image of the south-eastern area of the crater wall from the centre of the main crater floor. Note the discoloured ash oxidation high up on the crater wall. $\mathbf{d}$ The eastern edge of the pyroclastic surge deposit. Note the medium grey-coloured outer margin of the deposit marking current lift-off 

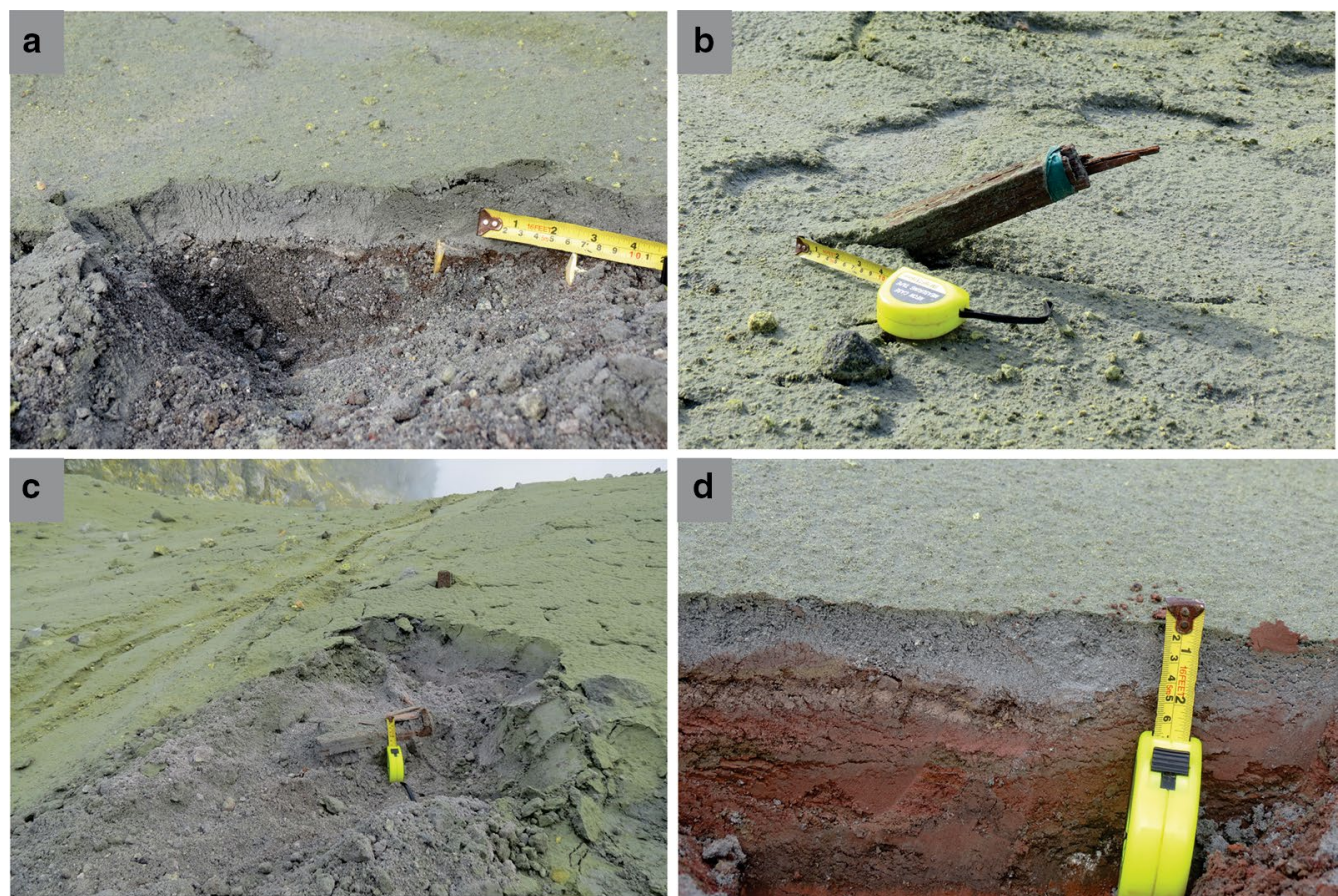

Fig. 7 Field images of the pyroclastic density current (PDC) and the impacts on pre-existing field markers. a Sheared yellow plastic pegs at the PDC base are clearly evident, as well as damaged wooden stakes (b and $\mathbf{c}$ ) that are broken and now leaning or snapped away from the crater lake. $\mathbf{d}$ The deposit exhibits a weakly erosional basal contact and is fine-grained and poorly to very poorly sorted

Table 3 Best fit model parameters to the ballistic ejecta determined through over 110 model simulations

\begin{tabular}{|c|c|c|c|c|c|c|c|c|c|c|}
\hline \multirow{2}{*}{$\begin{array}{l}\text { Vent } \\
\text { Northern }\end{array}$} & \multicolumn{2}{|l|}{ No. of particles } & \multicolumn{2}{|c|}{$\begin{array}{l}\text { Particle density } \\
\left(\mathrm{kg} / \mathrm{m}^{3}\right)\end{array}$} & Density s.d & \multirow{2}{*}{$\begin{array}{l}\text { Bearing } \\
110\end{array}$} & \multicolumn{2}{|c|}{ Drag coefficient } & $\begin{array}{l}\text { Initial flow } \\
\text { velocity }(\mathrm{m} / \mathrm{s})\end{array}$ & $\begin{array}{l}\text { Flow } \\
\text { range } \\
\text { (m) }\end{array}$ \\
\hline & 270,000 & & 1691 & & 311 & & 0.7 & & 65 & 30 \\
\hline Eastern & 124,500 & & 1691 & & 311 & 114 & 0.7 & & 58 & 25 \\
\hline Eastern & 53,300 & & 1691 & & 311 & 114 & 0.7 & & 50 & 20 \\
\hline \multicolumn{3}{|c|}{ Particle diameter (m) } & & \multicolumn{3}{|c|}{ Displacement from vent centre (m) } & \multicolumn{2}{|c|}{ Initial velocity (m/s) } & \multicolumn{2}{|c|}{$\begin{array}{l}\text { Ejection angle } \\
\text { (from vertical) }\end{array}$} \\
\hline Average & SD & Range & & Average & SD & Max & Average & SD & Average & SD \\
\hline 0.0791 & 0.042 & $0.05-0.422$ & & 4 & 3 & 8.138 & 65 & 5 & 60 & 10 \\
\hline 0.0791 & 0.042 & $0.05-0.422$ & & 3 & 2 & 6 & 58 & 5 & 60 & 10 \\
\hline 0.0791 & 0.042 & $0.05-0.422$ & & 3 & 2 & 6 & 50 & 5 & 60 & 10 \\
\hline
\end{tabular}

(yellow plastic pegs). We observed four plastic pegs that were sheared off, including near the margins of the deposit, while two wooden stakes were snapped and bent away from the vent area. Secondly, the distribution of the ash deposit is almost identical to the surge recorded in the October 2013 eruption that was observed via lowlight camera from the old sulphur factory (Fig. 1). Images taken during that eruption clearly show the flow of a density current towards the camera at a rate of $\sim 10 \mathrm{~m} \mathrm{~s}^{-1}$
(Kilgour and Bowyer 2015). Moreover, field observations of that eruption deposit showed clear signs of topographic run-up from a density current. Therefore, based on the above descriptions and similar deposit distribution, we interpret the ash deposit to have been emplaced by a dilute pyroclastic density current, i.e. a pyroclastic surge.

Near the inner crater wall, to the south and east of Donald Mound, we note common impact craters that 

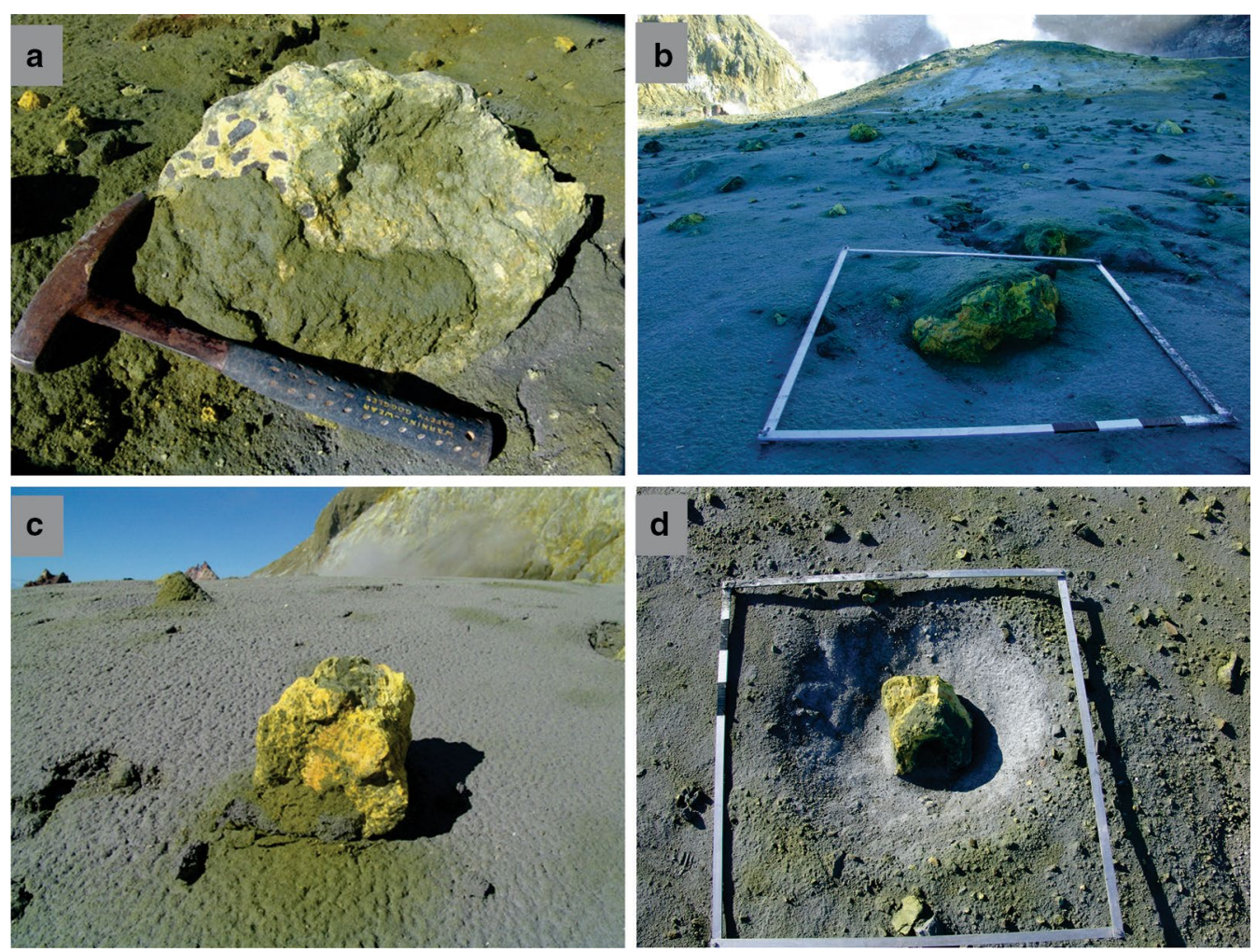

Fig. 8 A collection of ballistic types seen in the field. a An intensely altered breccia block is partially covered by the waning stages of the pyroclastic surge. $\mathbf{b}$ A near complete covering by the near-end stages of the surge blankets the breccia ballistic. $\mathbf{c}$ A solitary hydrothermally altered ballistic that has no clear sign of a ballistic crater, presumably due to crater infilling and/or near simultaneous ejection of ballistics and surge. $\mathbf{d}$ A clear ballistic impact crater within $130 \mathrm{~m}$ of the inner crater wall

were clearly generated during this eruption sequence (Fig. 6). In about half of the impact craters, a ballistic clast was found (Fig. 8). In two locations, we dug pits to search for the responsible clasts and found them to be buried to a depth of $\sim 200 \mathrm{~mm}$. Using images obtained from our field visits and those from the tour operators (a tourist boat made a visit to the island on the day after the eruption), we see that many ballistics are partially covered by relatively fine-grained surge deposits-we expand on this observation later in the image analysis section below.

A rather striking feature of this eruption deposit is the common presence of bright yellow breccia clasts (Fig. 9). The composition of the ejecta is essentially bimodal, including a sulphate-dominated breccia and a weakly altered, lava and sediment lithology. Ranging in size from 50 to $300 \mathrm{~mm}$ across, these clasts are distinctive and are rarely seen in recent eruption deposits. Variably brecciated andesite lavas, covering a wide range in alteration intensities from essentially fresh to intensely altered, are characteristic of both the surge and ballistic deposits.

\section{Deposit distribution and volume calculations}

Thickness measurements of the deposit over a broad section of the crater floor ranged from $\sim 5$ to $200 \mathrm{~mm}$. We use these thicknesses to derive an isopach map of the deposit and its volume (Fig. 10). The volume is calculated using the definite integral of an exponential decay curve derived from the isopach area and thickness. From this, we calculate a volume of $\sim 13,200 \mathrm{~m}^{3}$, although this value is seemingly precise, it is difficult to assess the error on this calculation due to the limited measurements obtained and so the error could be significant.

It is also important to note the effect of the $\sim 20$-m-high crater wall on the outflow of the pyroclastic surge during this eruption. Analogue modelling has shown that tall barriers significantly impede density current flow (e.g. Lane-Serff et al. 1995), and here, we suggest this is certainly the case. Such a barrier will cause much of the flow to rebound off the inner crater wall back into the vent area while only a small portion of the flow will surmount the barrier and flow along the main crater floor. Our volume estimate is solely on the extra-crater deposit, and it is possible that our volume calculation is but a fraction 

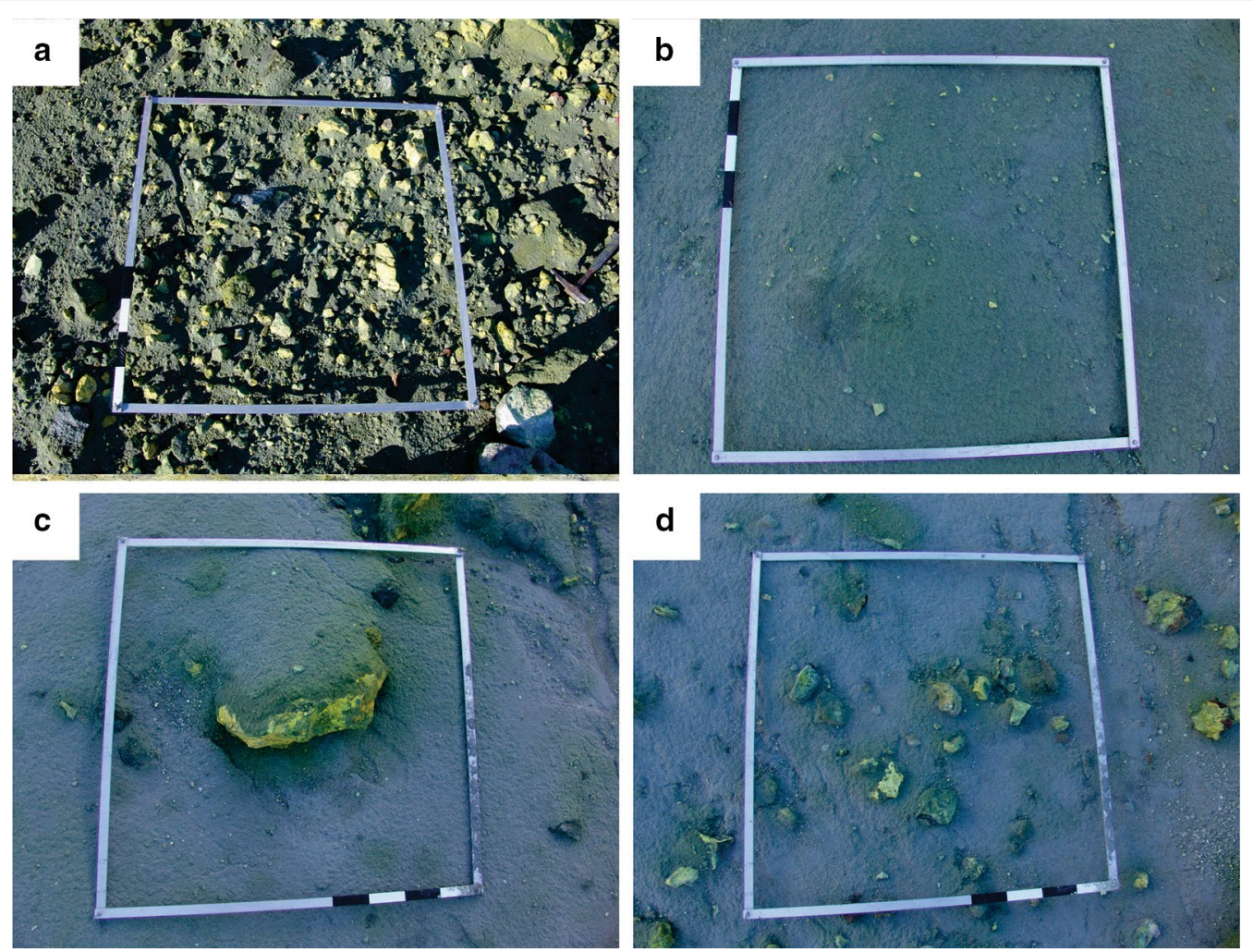

Fig. 9 The use of an aluminium picture frame that is $1 \mathrm{~m}^{2}$ provides a rapid reconnaissance tool for collecting highly variable ballistic ejecta images with limited exposure time

of the total surge deposit. It is difficult to estimate what fraction of the total we have captured, because we have no information about the height of the flow relative to the barrier. However, based on analogue experiments (e.g. Lane-Serff et al. 1995), we estimate $5-10 \%$ of the flow never left the crater making the overall total closer to $65,000 \mathrm{~m}^{3}$.

Delineating the ballistic ejecta required both groundbased assessments and image analysis. Firstly, the ballistic ejecta reaches a distance of $\sim 200 \mathrm{~m}$ from the inner crater wall, which is $\sim 300 \mathrm{~m}$ from the implied vent area (see ballistic modelling section below) and the distribution of ballistics is non-uniform. A clear example of this is seen on the lee side of Donald Mound, where a small area $\left(10-15 \mathrm{~m}^{2}\right)$ is free of ballistics, indicating directional shadowing (Fig. 6). Larger blocks are generally found near the inner crater wall and within $\sim 100 \mathrm{~m}$ of the inner crater wall.

\section{Image analysis of eruption deposits}

The spatial distribution of the number and the mean size of ballistics is presented for all clasts (Fig. 11a) and for only clasts greater than $5 \mathrm{~cm}$ (Fig. 11b), which is a typical cutoff for clasts that are more likely to have followed a ballistic trajectory. In both cases, squares with zero ballistics (empty circles) track a deposit elongated to the ESE. When all clasts are considered, the extent of the ballistic field is extended to the ESE and the number of encompassed blocks increases (Fig. 11a, b) while grain size decreases (Fig. 11c, d). The total size distribution for clasts at close distances, e.g. site 10, and far sites, e.g. site 33, shows a markedly different shape (Fig. 12).

The distribution of clasts $>5 \mathrm{~cm}$ does not show a classic bullseye pattern with a systematic decrease in number away from a single central point or axis as would be indicated by a single ballistic event with normally distributed eruption parameters (Fig. 12) (e.g. Druitt et al. 2002). In addition, the northern area of the map has fewer $>5 \mathrm{~cm}$ ballistics per square metre $\left(\mathrm{b} \mathrm{m}^{-2}\right)$ ranging from 1 to 16 $\mathrm{b} \mathrm{m}^{-2}$ while the southern area and central area have relatively high spatial densities of blocks from 9 to $38 \mathrm{~b} \mathrm{~m}^{-2}$. High spatial variation within small areas is evident from site locations such as site 11 and 10 (Fig. 13) which are the closest locations to the crater edge and situated only $5.5 \mathrm{~m}$ apart. Despite the proximity of the sites, the density of clasts varies by 20 clasts per metre squared (site 10 has $38 \mathrm{~b} \mathrm{~m}^{-2}$, site $11-18 \mathrm{~b} \mathrm{~m}^{-2}$ ). The average size data do not show a convincing systematic increase away from the 


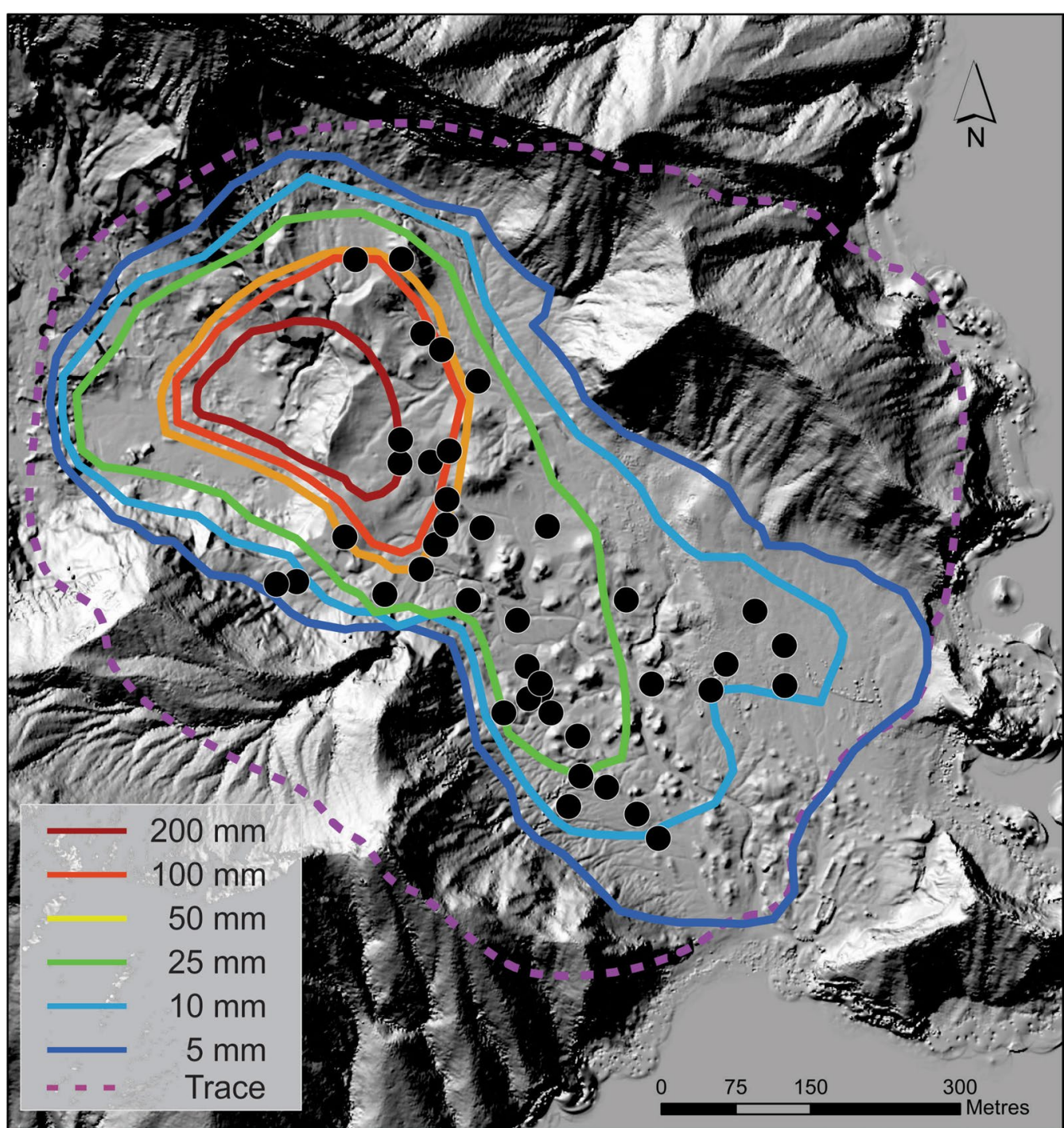

Fig. 10 Isopach map of the pyroclastic surge component of the eruption. This was created using thickness data from two separate field visits and aerial images of the deposit distribution. Note the thickest part of the deposit coincides with the high topographic feature-Donald Mound. We have also traced the inflated co-surge plume using aerial images up on the crater walls

vent as predicted by purely ballistic models (de Michiele Vitturi et al. 2010).

\section{Modelling results}

A total of 116 model iterations were undertaken before the final best fit model was selected (Table 3). Thirtyfive runs investigated the influence of parameters such as gas flow radius, gas flow speed, bearing and ejection speed on block deposition. A total of 30 model runs were undertaken for the single-burst Scenario 1, developed to investigate the maximum $E_{\mathrm{k}}$ release and to discern if a single burst could be responsible for the observed block field. A total of 51 runs were completed of the multi-burst Scenario 2 until a sufficient fit was found. The greater number of runs of the second multi-burst scenario reflects the increased complexity of modelling three bursts.

Fitting the model runs was an iterative process using the number of blocks per $\mathrm{m}^{2}$ and the field shape. To fit the model to field observations, we had to consider the effects of variable topography on the final clast density. For example, behind Donald Mound (Fig. 1b) there were few blocks mapped, despite the locations proximity to the vents. This suggests a shadow depositional zone due to the topographic barrier of Donald Mound (c.f. Kilgour et al. 2010). Model iterations were unable to reproduce 

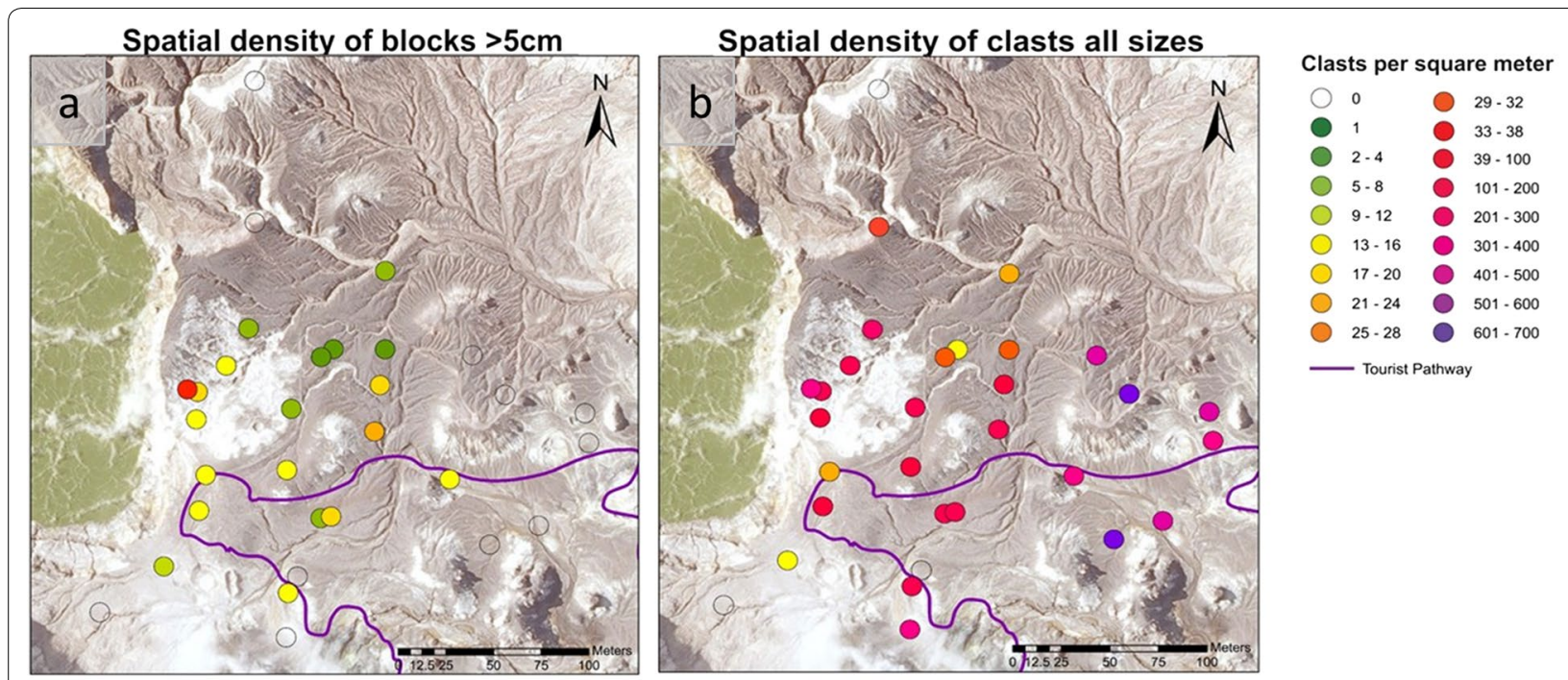

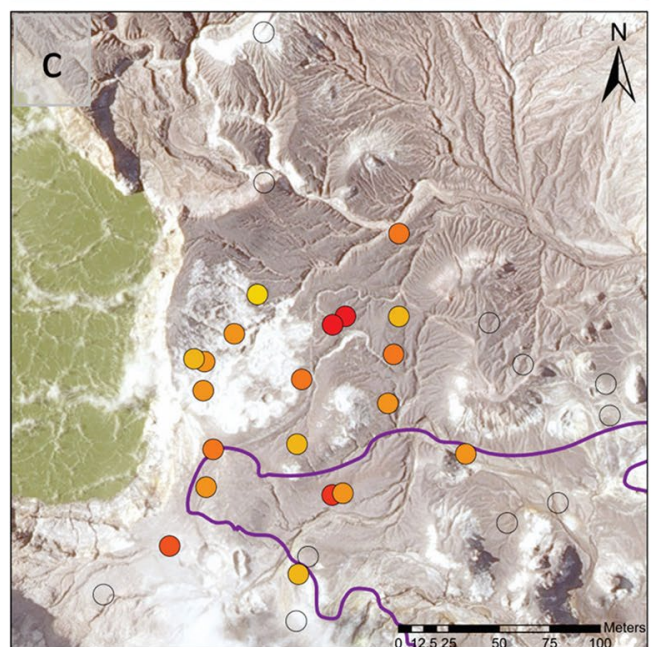

Average diameter of blocks $>5 \mathrm{~cm}$

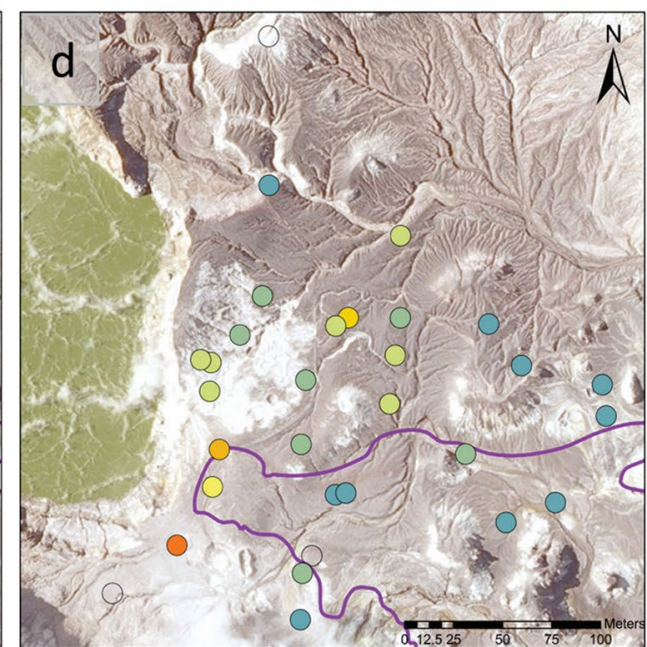

Average diameter of clasts all sizes

Fig. 11 Maps illustrating the distribution of $\mathbf{a}$ number of all mappable clasts at all surveyed sites, $\mathbf{b}$ the number of only clasts $>5 \mathrm{~cm}$ diameter, $\mathbf{c}$ the average diameter of clasts $>5 \mathrm{~cm}$ at all surveyed sites and $\mathbf{d}$ the average diameter of all clasts at all surveyed sites

this shadow effect at ejection angles greater than $30^{\circ}$ from horizontal from each vent, and hence, an ejection angle of $30^{\circ}$ was iteratively chosen and remained constant for each burst. We matched the measured to the modelled number of $\mathrm{b} \mathrm{m}^{-2}$ in every location through a large number of model runs (Fig. 13). Multi-burst scenarios were not only consistent with geophysics but also produced a better fit to the spatial density data. Contrastingly, a single-burst scenario produced a single strip with very high clast number density and could not reproduce the high localised variability. The single-burst Scenario 1 (Fig. 13a, b) reproduced the furthest extent location (i.e. site 33) and the elongated field shape (Fig. 13c, d). However, Scenario 1 did not reproduce the relatively sharp edge of the ballistic distribution seen in the field and consistently had many blocks beyond the mapped outline.

Run 64 for Scenario 2 was chosen as the best fit scenario as the model data deviated the least from the mapped field data (Fig. 13d). 79.3\% of the site locations were within 2 ballistics per metre squared of the observed clasts density with $65.5 \%$ matching the mapped data exactly.

While this model produces a good fit to the observed data, it is limited in that it does not replicate the elongated distribution seen in the field. Further models were run in an attempt to rectify this; however, we have been unable to improve the model without negatively impacting the fit of all other model points. 


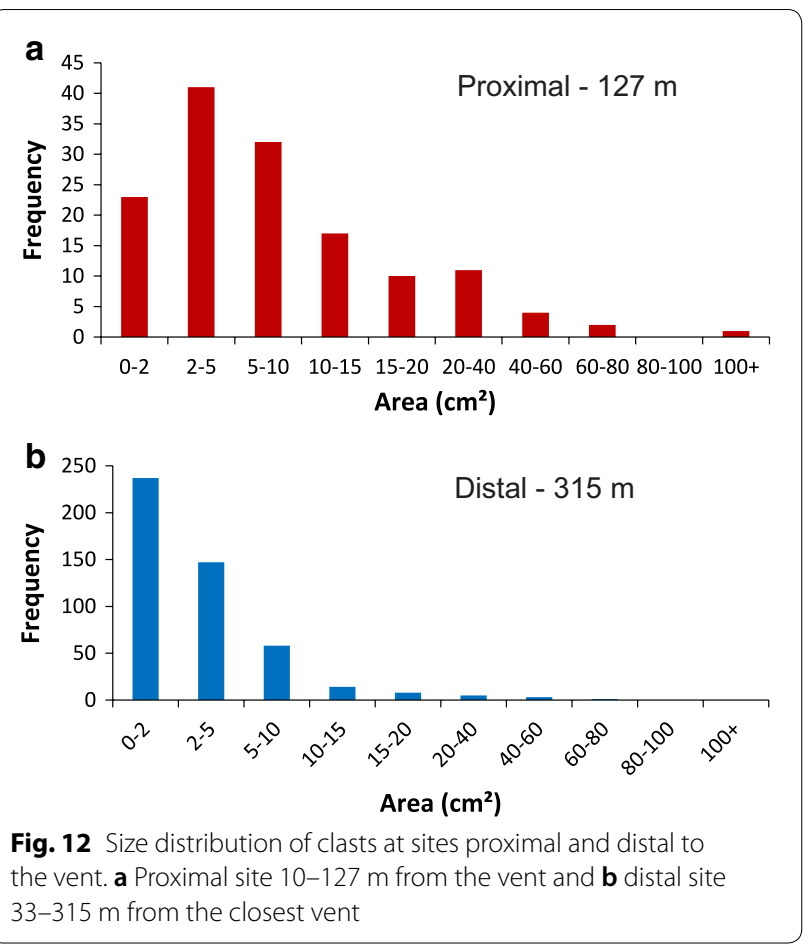

\section{Discussion}

\section{Eruption model}

To explain the complexity of this eruption, we rely on field, geophysical and modelling data for a directed eruption from multiple vents, involving multiple ballistic and surge generating pulses. Multiple pulses of eruption are primarily supported by the seismo-acoustic data (Walsh et al. 2019), while the directionality is derived from both field and modelling data. Few phreatic eruptions have been analysed in detail exceptions being the eruption of Ruapehu in 2007 (Kilgour et al. 2010), Te Maari 2012 (Fitzgerald et al. 2014)-both from New Zealand-and the Ontake eruption in 2014 (e.g. Maeno et al. 2016; Tsunematsu et al. 2016). During those events, each eruption was observed (Kilgour et al. 2010; Lube et al. 2014) recorded (Jolly et al. 2014; Kaneko et al. 2016) and modelled (Fitzgerald et al. 2014; Tsunematsu et al. 2016), providing a dataset for comparing and exploring small yet complex eruptions.

The size distribution of the blocks ejected at White Island does not show a systematic size distribution with distance from vent. However, if $<5 \mathrm{~cm}$ clasts are included as ballistics, there is a systematic overall decrease in diameter with distance from the vent (Fig. 13), a distribution observed with ballistics from phreatomagmatic eruptions which have significant influence from a gas jet phase (Lorenz 1970; Self et al. 1980; Waitt et al. 1995; Sottilli et al. 2012). The decreasing particle size with distance in phreatomagmatic eruptions has been suggested to be due to the impact of a gas flow region, reducing the drag upon the ejected particles (Lorenz 1970; Taddeucci et al. 2017). Therefore, we suggest that a significant gas flow region was present during each phreatic pulse and is similarly important in phreatic as well as phreatomagmatic eruptions. Indeed, we suggest that the additional ballistic transport of small particle may have been exacerbated by the directed surges in one or more pulses.

Coupled multiple ballistic and surge pulses are supported by the field relations in the eruption deposits. Ballistic blocks clearly lie on top of the bulk of the surge deposit, creating few impact craters. Impact craters seen near the crater wall suggest that the relative time between surge and ballistics was similar, with the surge depositing marginally before the bulk of the ballistics landed. Subsequent, yet partial burial of later ballistics additionally occurs near the end of surge deposition. Furthermore, the commensurate eastward-directed mapped distribution of both deposit types indicates that both ballistic and density current/s were initiated at the same time. This indicates that the ballistic and particle-laden plume, later forming the surge(s), were possibly coupled, with ballistics ejected at $\sim 30^{\circ}$ angle from horizontal (Fig. 14). The implications of this are significant for two reasons: (1) the vent was significantly inclined and stable enough to eject at least one, but more likely two to three pulses; and (2) a water and particle-laden plume that later flowed as a surge was ejected into and on top of the crater wall. We envisage a scenario that includes a low-angle plume that interacted with the crater wall to generate both a secondary, partially buoyant plume that is relatively over-inflated and a density current that flows slowly along the main crater floor towards the sea. The inflated plume is transported with the low-level winds broadly confined by the outer crater walls, resulting in ash deposition high on the crater wall slopes, while the surge is focussed by the steep topography and the initial momentum to the east. These thin surge and secondary fall deposits are unlikely to be preserved in the geological record and could be a common feature at many eruptions. This is especially likely where directed plumes and density currents encounter near-vent crater rims or uneven topography during small and large volume eruptions. Knowledge of this depositional mechanism will be used later to constrain the hazard posed by this specific eruption, but clearly, this has much broader implications globally, especially given the rather common occurrence of crater walls bounding vent areas.

\section{Energetics of ballistic and surge emplacement}

We now consider the energetics of emplacement for this eruption and examine how this compares to the 

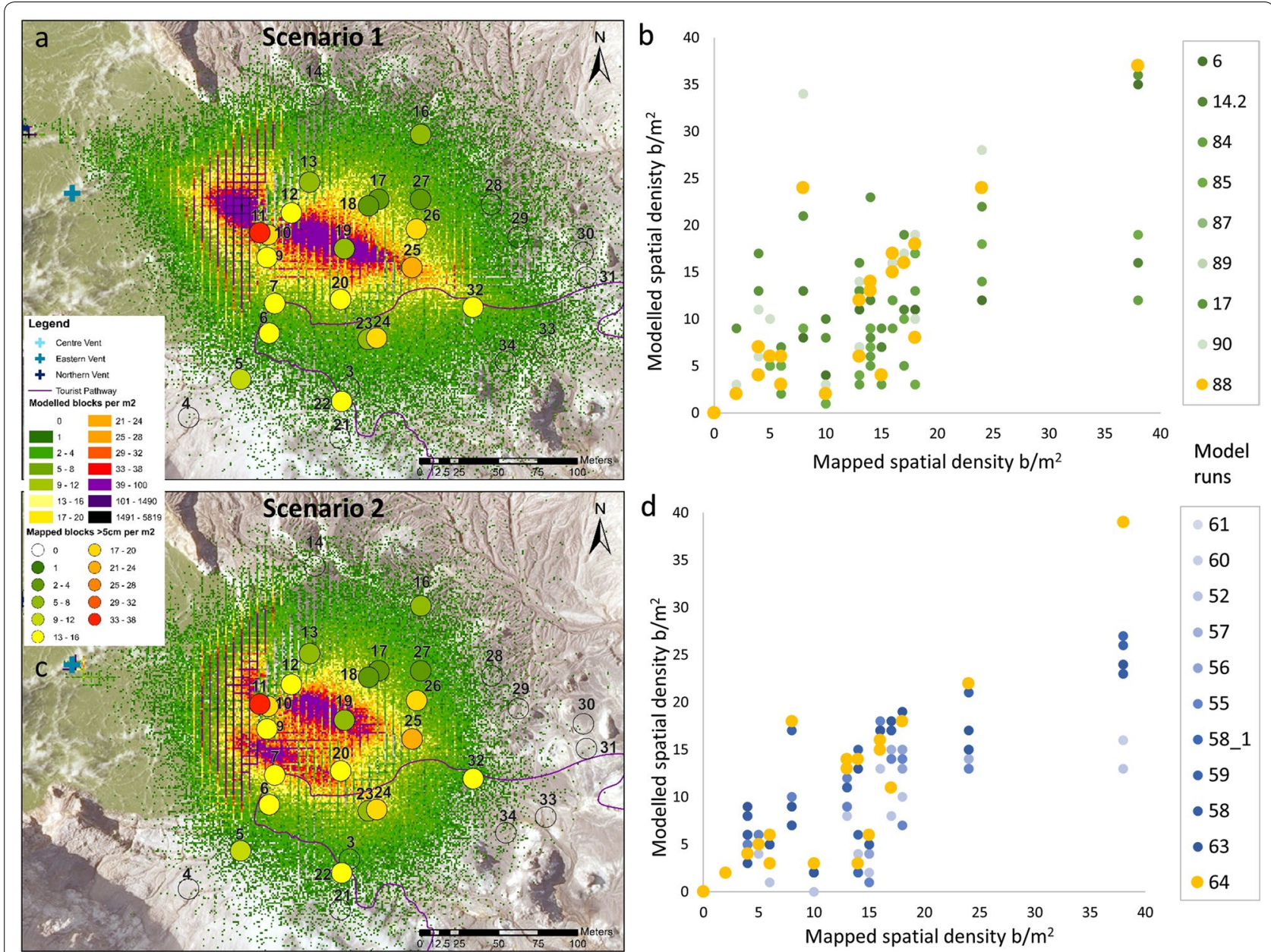

Fig. 13 a The mapped results from the best fit single eruption pulse Ballista model showing the number of modelled ballistics per square metre. The number of mapped ballistics $>5 \mathrm{~cm}$ from Fig. 11a are also shown for comparison with the corresponding site number. b A comparison of the modelled spatial density for Scenario 1 with field spatial density at each sample location. Each example model run is shown as different coloured points, the best model iteration is shown in yellow. c The mapped results for the three-pulse scenario. $\mathbf{d}$ Example model iterations and best fit for the three-pulse scenario

instantaneous energy at the vent. We do this as a way of directly comparing this eruption to other similar events but also to inform the potential hazard for future analysis.

The output file from Ballista model runs provides velocities, size distribution and measured density, which together are used to estimate the total energy of the three ballistic pulses totalling 448,300 ballistics as $2.2 \times 10^{7}$ J. For this, we use the standard kinetic energy formula that considers the mass of material and its velocity (i.e. Eq. 1). The best fit single pulse requires more particles and higher velocities and consequently higher energy $\left(3.1 \times 10^{7} \mathrm{~J}\right)$. Both energy estimates are significantly greater than values obtained if only the mapped ballistics were used, as the model includes the unmappable ballistics that would have landed in the lake.
When we calculate the kinetic energy of the surge portion of the eruption, we are constrained to the extracrater deposits due to accessibility. This is because a substantial portion of the deposit is likely confined to the inner crater, by the $\sim 20$-m-high crater wall. Additionally, there are no visual observations of the eruption to assess the flow velocity. Taken together, these limitations mean that the results of our calculations are underestimated.

To address the lack of visual observations, we use unpublished data (Kilgour and Bowyer 2015) obtained from a similar-sized eruption at White Island on 13 October 2013. During that event, a radial ballistic apron was ejected from a similar vent location and a surge was generated and observed using a low-light web camera near the old sulphur factory. We use this as a suitable analogue because the run-out distance of that surge is 


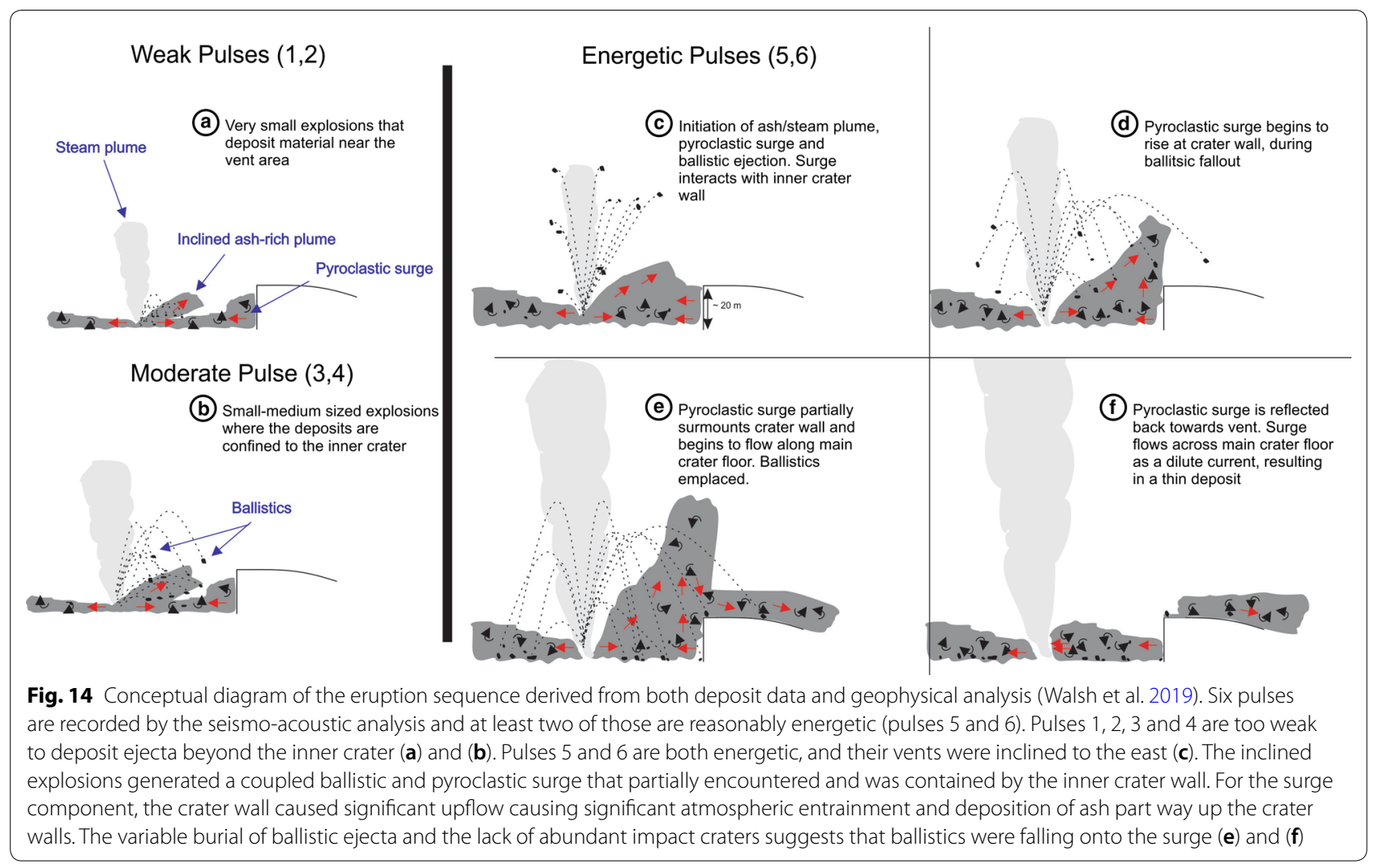

almost identical to the 2016 deposit. Using the $1 \mathrm{~s}$ camera images, the flow velocity towards the camera, i.e. eastwards, is $\sim 11 \mathrm{~m} \mathrm{~s}^{-1}$. Using this flow velocity, and the mass and volume of the deposit from the thickness measurements, the calculated kinetic energy has a range between $3.3 \times 10^{8} \mathrm{~J}$ and $5.9 \times 10^{8} \mathrm{~J}$, using a bulk density of 500 and $900 \mathrm{~kg} \mathrm{~m}^{-3}$, respectively. These energy values are similar to the ballistic energy, but as mentioned above, this calculation is only for the extra-crater pyroclastic surge and discounts the energy partitioned into the plume, and the portion potentially inflated due to crater rim interaction. Therefore, when we consider the volumetrically dominant yet inaccessible component of the deposit (we estimate between 80 and $90 \%$ of the total deposit stayed in the lake), we obtain an order of magnitude greater energy release.

Depending strongly on the proportion of surge that is unable to surmount the crater rim, the energy of the eruption is dominated by the pyroclastic surge. Therefore, when we sum the energies, the overall kinetic energy is between $\sim 4 \times 10^{8}$ and $6 \times 10^{9} \mathrm{~J}$. We now use this to compare against other eruptions to place this event in some context. Few studies have examined the energetics of eruptions, at least determined from deposit analysis. In contrast, a number of studies have examined the partitioning of seismic and acoustic energies (e.g. Hagerty et al. 2000; Palacios et al. 2016; Taddeucci et al. 2010). More recent analysis of eruption energetics through combined field and laboratory analysis provides some basis for comparison, especially for relatively small, multi-pulse, phreatic eruptions (e.g. Fitzgerald et al. 2014; Lube et al. 2014; Montanaro et al. 2016a). The Te Maari eruption of Tongariro in 2012 ejected ballistic ejecta at $\sim 200 \mathrm{~m} \mathrm{~s}^{-1}$ initiated with a kinetic energy of $\sim 1.0 \times 10^{9}$ J (Fitzgerald et al. 2014) coincident with a pyroclastic surge that travelled $\sim 80 \mathrm{~m} \mathrm{~s}^{-1}$, equating to $\sim 1 \times 10^{12} \mathrm{~J}$ (Lube et al. 2014). These values for the Te Maari eruption are at least two orders of magnitude larger than the White Island eruption described here. Due to the lack of complete deposit access at White Island, we are unable to confidently compare directly. Nevertheless, the relatively low energy of this eruption suggests that the seal confining the pressured fluids and gas and the total volume and pressure of the pressurised fluids volume was relatively limited compared to the hydrothermal system at Te Maari.

\section{Hazard footprint of the White Island 2016 eruption}

White Island is a popular tourist destination, and during the day at any given time, more than 100 people can be distributed along the path on the main crater floor. The track takes the tourists from the factory up to the crater 


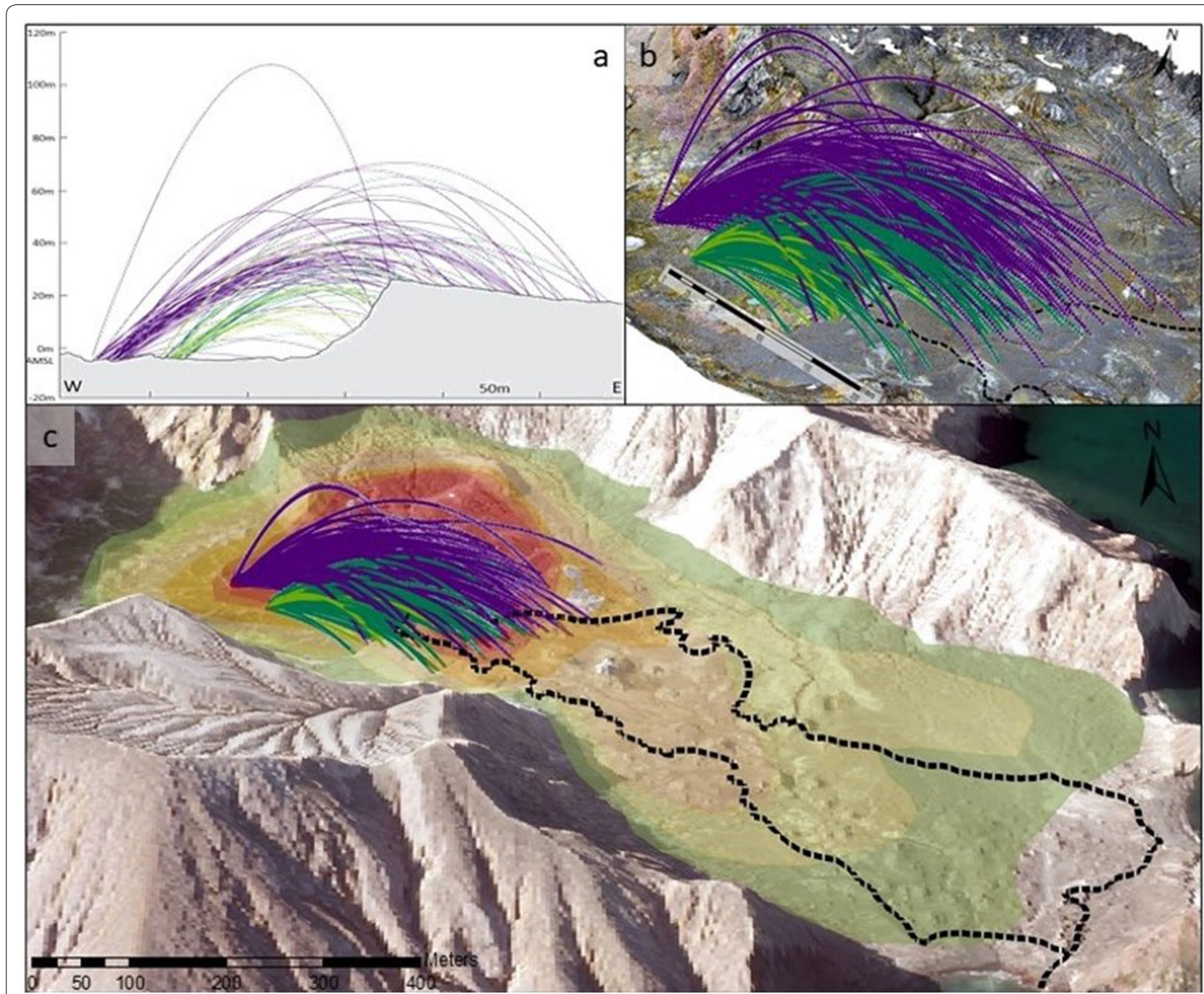

Fig. 15 Particle trajectory and its use in determining the hazard footprint of the eruption. Pulse 6 trajectories are dark purple, dark green trajectories represent Pulse 5, and light green Pulse 4. The number of particles shown have been reduced for figure clarity, number remains proportional to that modelled. a 2D trajectory figure showing 50 particles for Pulse 6, 23 for Pulse 5, 10 for Pulse 4. Created by Dale Cusack b 3D ballistic trajectories, 100 particles P6, 46 for Pulse 5, 20 for Pulse 4. Created in ArcScene. c The ballistic trajectories overlain with surge isopachs and tourist pathway

edge and then back along a looped path (Fig. 15). The usual exposure time is confined to between 1 and $1.5 \mathrm{~h}$, depending on the tour type. (Helicopter tours allow the tourists $\sim 1 \mathrm{~h}$, while the boat trips are $\sim 1.5 \mathrm{~h}$ on island.) Using the tour track information, we examine both the ballistic ejecta and pyroclastic surge inundation areas to explore the hazard footprint that includes broad emplacement rates through the eruption.

The footprint of the ballistic hazard of $\sim 98,000 \mathrm{~m}^{2}$ and surge hazard of $331,000 \mathrm{~m}^{2}$ corresponds to similar sections of track within approximately $360 \mathrm{~m}$ of the main crater. This is approximately $28.6 \%(568 \mathrm{~m})$ of the path used by tourist operators (Fig. 15). For the ballistic ejecta, we note fine-scale variations in the clast number density. This is clearly delineated in Fig. 13, where the distribution of ejecta extends to the northern part of the tourist track. There, the number of ballistic clasts (up to 100 clasts per $\mathrm{m}^{2}$ ) is very high, clearly indicating that the dispersal axis is significantly more hazardous than the margins. Furthermore, the ejecta apron extends up to $200 \mathrm{~m}$ from the inner crater wall, during this directed eruption. Therefore, future considerations of phreatic eruption hazards at White Island will need to consider the potential for directed eruptions, PDC funnelling, and the potential for these eruptions to eject large volumes and high number density ballistics.

Approximately $95 \%$ of the tourist path is affected by the pyroclastic surge, and using a similar-sized eruption, we estimate the flow velocity to be $\sim 11 \mathrm{~m} \mathrm{~s}^{-1}$. Using the equations of Clarke and Voight (2000) (Eq. 2), the White 
Island case studied here leads to dynamic pressures $\left(P_{\mathrm{dyn}}\right)$ of between $\sim 30$ and $350 \mathrm{kPa}$.

$$
P_{\text {dyn }}=\frac{M_{\text {ult,yield }}}{r h^{2} C_{\mathrm{d}}}
$$

where $M_{\text {ult }}$ is the ultimate bending moment of failure, $M_{\text {yield }}$ is the yield bending moment, $r$ is the stake or peg radius, $h$ is the height, and $C_{\mathrm{d}}$ is the drag coefficient. For the wooden stakes, we used values for the moment of failure for a Japanese cedar to be $1.36 \times 10^{7} \mathrm{~kg} \mathrm{~m}^{2}$ $\mathrm{s}^{-2}$, a radius of $12 \mathrm{~cm}$, height of $30 \mathrm{~cm}$, which equates to $\sim 340 \mathrm{kPa}$.

Some uncertainty arises from the true value of bending moment failure (one order of magnitude lower equates to an order of magnitude lower dynamic pressure) for both the plastic and wooden pegs due to their exposure to sustained sunlight and acidic gases, respectively. Nevertheless, this range in dynamic pressures would cause significant infrastructural damage and inflict significant wounds to tourists had they been there at the time. One obvious mitigating factor that reduces the hazard posed from relatively slow moving, pyroclastic surges is the distance from the vent. The large volume of material deposition near the crater rim significantly reduces the flow velocity, and towards the point of lift-off, the surge is very dilute. Therefore, the hazard posed by the surge portion of the eruption is generally restricted to the deposit outline and not beyond, despite probable ash distribution confined by the main crater walls.

\section{Conclusions}

This work has shown that small phreatic eruptions can be driven by multiple pulses of explosions that generate penecontemporaneous plumes, at least one pyroclastic density current and multiple ballistic ejecta. The surge was both directed to the $\mathrm{E}$ over and modified by the $\sim 20$-m-high inner crater wall. This significant topographic barrier caused the flow to inflate significantly, causing relatively buoyant dispersal onto the upper margins of the steep, inner crater walls that surround the bulk of the island. The density current progressed slowly along the main crater floor, probably due to the substantial portion of rock fragments depositing out near the crater rim. Reaching 650 from the inner crater wall, the pyroclastic surge flowed along the main crater floor until complete atmospheric mixing lofted the current into the atmosphere. Based on the deposit volume, this flow was minor compared to global examples. As for the ballistic ejecta, the deposit mapping highlighted areas of high clast density that cannot be explained by a single ballistic event. Instead, our numerical modelling shows that at least three of the six pulses generated ballistics with an ejection velocity of
$50-65 \mathrm{~m} \mathrm{~s}^{-1}$. Using a numerical ballistic modelling codeBallista, we found that the kinetic energy is very low when compared to global equivalents and may be on the lowest end of eruptions analysed in any detail.

This study provides a quantitative assessment of the eruption and the hazards that these events pose, with specific reference to tourists on White Island. Therefore, this work can be directly inputted into useful risk models elsewhere where phreatic eruptions are common. In the case of White Island, we have developed a time-varying hazard footprint of these regular, albeit small eruptions and the tools used to model this event can be up-scaled to assess larger eruption hazards.

Lastly, deposit mapping and modelling work has proven to be a useful exercise in deriving eruption processes during a low-energy, phreatic eruption. This is useful because these types of eruptions are both hazardous and common at active volcanoes, yet their deposits are often eroded rapidly. Therefore, if we are to truly document the hazard at active volcanoes, we must consider these small events in concert with much larger events that are geologically preserved. In time, this may allow us to create a true account of the hazard posed at frequently active and long-lived volcanoes.

\section{Authors' contributions}

GK completed the fieldwork and collected samples, took images, and led the pyroclastic surge analysis. SG led the ballistic modelling component with BK. AM and AF conducted image analysis of the field images. CA completed the drone-based digital surface model. GK, SG and BK collaborated on the conceptual model and the writing. All authors read and approved the final manuscript.

\section{Author details}

1 GNS Science, Wairakei Research Centre, 114 Karetoto Rd, Taupo, New Zealand. ${ }^{2}$ Department of Geological Sciences, University of Canterbury, Private Bag 4800, Christchurch 8140, New Zealand.

\section{Acknowledgements}

We thank Michael Rosenberg and Brad Scott for discussion on the eruption deposits and processes. The two anonymous reviewers provided constructive suggestions that improved the clarity of the manuscript.

\section{Competing interests}

The authors declare that they have no competing interests.

Availability of data and materials

Please contact author for data requests.

\section{Funding}

This research was supported by New Zealand Strategic Science Investment Funding (SSIF) from the New Zealand Ministry of Business and Innovation (MBIE). EQC provided support for the ballistic analysis.

\section{Publisher's Note}

Springer Nature remains neutral with regard to jurisdictional claims in published maps and institutional affiliations.

Received: 12 June 2018 Accepted: 25 February 2019

Published online: 01 April 2019 


\section{References}

Alatorre-lbergüengoitia MA, Delgado-Granados H (2006) Experimental determination of drag coefficient for volcanic materials: calibration and application of a model to Popocatépetl volcano (Mexico) ballistic projectiles. Geophys Res Lett 33(11):L11302

Barberi F, Bertagnini A, Landi P, Principe C (1992) A review on phreatic eruptions and their precursors. J Volcanol Geotherm Res 52:231-246

Breard ECP, Lube G, Cronin SJ, Fitzgerald R, Kennedy B, Scheu B, Montanaro C, White JDL, Tost M, Proctor JN, Moebis A (2014) Using the spatial distribution and lithology of ballistic blocks to interpret eruption sequence and dynamics: August 62012 Upper Te Maari eruption, New Zealand. J Volcanol Geotherm Res 286:373-386

Browne PRL, Lawless JV (2001) Characteristics of hydrothermal eruptions, with examples from New Zealand and elsewhere. Earth Sci Rev 52(2):299-331

Chardot L, Jolly A, Kennedy B, Fournier N, Sherburn S (2015) Using volcanic tremor for eruption forecasting at White Island volcano (Whakaari), New Zealand. J Volcanol Geotherm Res 302:11-23

Christenson BW, Reyes AG, Young R, Moebis A, Sherburn S, Cole-Baker J, Britten K (2010) Cyclic processes and factors leading to phreatic eruption events: insights from the 25 September 2007 eruption through Ruapehu crater lake, New Zealand. J Volcanol Geotherm Res 191:15-32

Clarke A, Voight B (2000) Pyroclastic current dynamic pressure from aerodynamics of tree or pole blow-down. J Volcanol Geotherm Res 100(1-4):395-412

Cole JW, Thordarson T, Burt RM (2000) Magma origin and evolution of White Island (Whakaari) volcano, Bay of Plenty, New Zealand. J Petrol 41(6):867-895

Crouch J, Pardo N, Miller CA (2015) Dual polarisation C-band weather radar imagery of the 6 August 2012 Te Maari Eruption, Mount Tongariro, New Zealand. J Volcanol Geotherm Res 286:415-436

de Michele Vitturi M, Neri A, Esposti Ongaro T, Lo Savio S, Boschi E (2010) Lagrangian modeling of large volcanic particles: application to vulcanian explosions. J Geophys Res 115(B8):B08206

de Moor JM, Aiuppa A, Pacheco J, Avard G, Kern C, Liuzzo M, Martínez M, Giudice G, Fischer TP (2016) Short-period volcanic gas precursors to phreatic eruptions: insights from Poás volcano, Costa Rica. Earth Planet Sci Lett 442:218-227

Deligne NI, Jolly GE, Taig T, Webb TH (2018) Evaluating life-safety risk for fieldwork on active volcanoes: the volcano life risk estimator (VoLREst), a volcano observatory's decision-support tool. J Appl Volcanol 7:7

Druitt TH, Young SR, Baptie B, Bonadonna C, Calder ES, Clarke AB, Cole PD, Harford CL, Herd RA, Luckett R, Ryan G, Voight B (2002) Episodes of cyclic Vulcanian explosive activity with fountain collapse at Soufriere Hills Volcano, Montserrat. In: Druitt TH, Kokelaar BP (eds) The eruption of Soufriere Hills Volcano, Montserrat from 1995 to 1999. The Geological Society of London, London, pp 281-306

Duncan AR (1970) The petrology and petrochemistry of andesite volcanoes in Eastern Bay of Plenty, New Zealand. Ph.D. Thesis, Victoria University of Wellington, New Zealand

Edwards M, Kennedy B, Jolly A, Scheu B, Jousset P (2017) Evolution of a small hydrothermal eruption episode through a mud pool of varying depth and rheology, White Island, New Zealand. Bull Volcanol 79:16

Esposito R, Hunter J, Schiffbauer JD, Shimizu N, Bodnar RJ (2014) An assessment of the reliability of melt inclusions as recorders of the pre-eruptive volatile content of magmas. Am Miner 99:976-998

Farquhar A (2018) Ballistic analysis inferring subsurface hydrothermal alteration and mineralogical seal control on eruptions at Whakaari volcano, New Zealand. Senior Bachelor thesis, Colorado College. Colorado Springs CO, USA

Fitzgerald RH, Tsunematsu K, Kennedy BM, Breard ECP, Lube G, Wilson TM, Jolly AD, Pawson J, Rosenberg MD, Cronin SJ (2014) The application of a calibrated 3D ballistic trajectory model to ballistic hazard assessments at Upper Te Maari, Tongariro. J Volcanol Geotherm Res 286:248-262

Fitzgerald RH, Kennedy BM, Wilson TM, Leonard G, Tsunematsu K, Keys H (2017) The communication and risk management of volcanic ballistic hazards. In: Fearnley CJ, Bird DK, Haynes K, McGuire WJ, Jolly G (eds) Observing the volcano world. Advances in volcanology-IAVCEI, Barcelona, Spain. Springer

Girona T, Huber C, Caudron C (2018) Sensitivity to lunar cycles prior to the 2007 eruption of Ruapehu volcano. Sci Rep 8:1476
Hagerty M, Schwartz SY, Garces MA, Protti M (2000) Analysis of seismic and acoustic observations at Arenal Volcano, Costa Rica, 1995-1997. J Volcanol Geotherm Res 101:27-65

Houghton BF, Nairn IA (1991) The 1976-1982 strombolian and phreatomagmatic eruptions of White Island, New Zealand: eruptive and depositional mechanisms at a 'wet' volcano. Bull Volcanol 54:25-49

Houghton BF, Scott BJ, Nairn IA, Wood CP (1983) Cyclic variation in eruption products, White Island volcano, New Zealand 1976-1979, New Zealand. J Geol Geophys 26:213-216

Jolly AD, Sherburn S, Jousset P, Kilgour G (2010) Eruption source processes derived from seismic and acoustic observations of the 25 September 2007 Ruapehu eruption-North Island, New Zealand. J Volcanol Geotherm Res 191:33-45

Jolly AD, Jousset P, Lyons JJ, Carniel R, Fournier N, Fry B, Miller CA (2014) Seismo-acoustic evidence for an avalanche driven phreatic eruption through a beheaded hydrothermal system: an example from the 2012 Tongariro eruption. J Volcanol Geotherm Res 286:331-347

Jolly AD, Kennedy B, Edwards M, Jousset P, Sheu B (2016) Infrasound tremor from bubble burst eruptions in the viscous shallow crater lake of White Island, New Zealand, and its implications for interpreting volcanic source processes. J Volcanol Geotherm Res 327:585-603

Kaneko T, Maeno F, Nakad S (2016) 2014 Mount Ontake eruption: characteristics of the phreatic eruption as inferred from aerial observations. Earth Planets Space 68:72. https://doi.org/10.1186/s40623-016-0452-y

Kato A, Terakawa T, Yamanaka Y, Maeda Y, Horikawa S, Matsuhiro K, Okuda T (2015) Preparatory and precursory processes leading up to the 2014 phreatic eruption of Mount Ontake, Japan. Earth Planets Space 67:111. https://doi.org/10.1186/s40623-015-0288-x

Kilgour GN, Bowyer E (2015) Recent eruption at White Island: quantifying the amount of material lost to the geological record. In: Holt KA (ed) Abstract Volume, GeoSciences 2014 Conference, 24th-27th November 2014, Pukekura Raceway and Function Centre, New Plymouth, New Zealand. Geoscience Society of New Zealand Miscellaneous Publication 139A

Kilgour GN, Manville V, Della Pasqua F, Graettinger A, Hodgson KA, Jolly GE (2010) The 25 September 2007 eruption of Mount Ruapehu, New Zealand: directed ballistics, surtseyan jets, and ice-slurry lahars. J Volcanol Geotherm Res 191:1-14

Kilgour GN, Moune S, Christenson B, Della Pasqua F (2016) Petrological insights into the 1976-2000 eruption episode of White Island, New Zealand: an eruption fuelled by repeated mafic recharge. EGU General Assembly, 17-22 April, 2016-Vienna, Austria

Lane-Serff GF, Beal LM, Hadfield TD (1995) Gravity current flow over obstacles. J Fluid Mech 292:39-53

Lorenz V (1970) Some aspects of the eruption mechanism of the Big Hole Maar, Central Oregon. Geol Soc Am Bull 81:1823-1830

Lube G, Breard ECP, Cronin SJ, Proctor JN, Brenna M, Moebis A, Pardo N, Stewart RB, Jolly AD, Fournier N (2014) Dynamics of Surges Generated by Hydrothermal Blasts during the 6 August 2012 Te Maari Eruption, Mt. Tongariro, New Zealand. J Volcanol Geotherm Res 286:348-366

Maeno F, Nakada S, Oikawa T, Yoshimoto M, Komori J, Ishizuka Y, Takeshita Y, Shimano T, Kaneko T, Nagai M (2016) Reconstruction of a phreatic eruption on 27 September 2014 at Ontake volcano, central Japan, based on proximal pyroclastic density current and fallout deposits. Earth Planets Space 68:82. https://doi.org/10.1186/s40623-016-0449-6

Mastin LG (2001) A simple calculator of ballistic trajectories for blocks ejected during volcanic eruptions. U.S. Geol Surv Open File Rep 01-45

Mayer K, Scheu B, Gilg A, Heap MJ, Kennedy BM, Lavallée Y, Letham-Brake M, Dingwell DB (2015) Experimental constraints on phreatic eruption processes at Whakaari (White Island volcano). J Volcanol Geotherm Res 302:150-162

Montanaro C, Scheu B, Gudmundsson MT, Vogfjörd K, Reynolds HI, Dürig T, Strehlow K, Rott S, Reusclé T, Dingwell DB (2016a) Multidisciplinary constraints of hydrothermal explosions based on the 2013 Gengissig lake events, Kverkfiöll volcano, Iceland. Earth Planet Sci Lett 434:308-319

Montanaro C, Scheu B, Mayer K, Orsi G, Moretti R, Isaia R, Dingwell DB (2016b) Experimental investigations on the explosivity of steam-driven eruptions: a case study of Solfatara volcano (Campi Flegrei). J Geophys Res 121(11):7996-8014

Oikawa T, Yoshimoto M, Nakada S, Maeno F, Komori J, Shimano T, Takeshita Y, Ishizuka Y, Ishimine $Y$ (2016) Reconstruction of the 2014 eruption sequence of Ontake Volcano (Ontake-san) from recorded images and 
interviews. Earth Planets Space 68:79. https://doi.org/10.1186/s4062 3-016-0458-5

Palacios PB, Díez M, Kendall J-M, Mader HM (2016) Seismic-acoustic energy partitioning during a paroxysmal eruptive phase of Tungurahua volcano, Ecuador. Geophs J Int 205:1900-1915

Plank T, Kelley KA, Zimmer MM, Hauri EH, Wallace PJ (2013) Why do mafic arc magmas contain 4 wt\% water on average? Earth Planet Sci Lett 364:168-179

Scott B (2013) A revised catalogue of Ruapehu volcano eruptive activity: 1830-2012. GNS Science Report 2013/45

Self S, Kienle J, Huot J (1980) Ukinrek Maars, Alaska, II. Deposits and formation of the 1977 craters. J Volcanol Geotherm Res 7:39-65

Sottilli G, Palladino DM, Gaeta M, Masotta M (2012) Origins and energetics of maar volcanoes: examples from the ultrapotassic Sabatini Volcanic District (Roman Province, Central Italy). Bull Volcanol 74:163-186

Strehlow K, Sandri L, Gottsmann JH, Kilgour GN, Rust AC, Tonini R (2017) Phreatic eruptions at crater lakes: occurrence statistics and probabilistic hazard forecast. J Appl Volcanol 6:4

Taddeucci J, Sottilli G, Palladino DM, Ventura G, Scarlato P (2010) A note on maar eruption energetics: current models and their application. Bull Volcanol 72:75-83

Taddeucci J, Alatorre-lbergüengoitia MA, Cruz-Vázquez O, Del Bello E, Scarlato P, Ricci T (2017) In-flight dynamics of volcanic ballistic projectiles. Rev Geophys 55:675-718

Tsunematsu K, Chopard B, Falcone J, Bonadonna C (2014) A numerical model of ballistic transport with collisions in a volcanic setting. Comput Geosci 63:62-69
Tsunematsu K, Ishimine Y, Kaneko T, Yoshimoto M, Fujii T, Yamaoka K (2016) Estimation of ballistic block landing energy during 2014 Mount Ontake eruption. Earth Planets Space 68:88. https://doi.org/10.1186/s4062 3-016-0463-8

Waitt RB, Mastin LG, Miller TP (1995) Ballistic showers during Crater Peak eruptions of Mount Spurr Volcano, summer 1992. In Keith TEC, The 1992 eruptions of Crater Peak vent, Mount Spurr Volcano, Alaska. US Geol Surv Bull 2139:89-106

Wallace P (2005) Volatiles in subduction zone magmas: concentrations and fluxes based on melt inclusion and volcanic gas data. J Volcanol Geotherm Res 140:217-240

Walsh B, Jolly AD, Proctor JN (2019) Geophysical examination of the 27 April 2016 Whakaari/White Island, New Zealand eruption and its implications for vent physiognomies and eruptive dynamics. Earth Planets Space 71:25. https://doi.org/10.1186/s40623-019-1003-0

Werner C, Hurst T, Scott B, Sherburn S, Christenson BW, Britten K, Cole-Baker J, Mullan B (2008) Variability of passive gas emissions, seismicity, and deformation during crater lake growth at White Island Volcano, New Zealand, 2002-2006. J Geophys Res 113:B01204

Williams GT, Kennedy BM, Wilson TM, Fitzgerald RH, Tsunematsu K, Teissier A (2017) Buildings verus ballistics: quantifying the vulnerability of buildings to volcanic ballistic impacts using field studies and pneumatic cannon experiments. J Volcanol Geotherm Res 343:171-180

\section{Submit your manuscript to a SpringerOpen ${ }^{\circ}$ journal and benefit from:}

- Convenient online submission

- Rigorous peer review

- Open access: articles freely available online

- High visibility within the field

- Retaining the copyright to your article

Submit your next manuscript at $\boldsymbol{\text { springeropen.com }}$ 